\title{
Article \\ Effects of Density Current, Diurnal Heating, and Local Terrain on the Mesoscale Environment Conducive to the Yarnell Hill Fire
}

\author{
Jan Ising ${ }^{1}\left(\mathbb{D}\right.$, Michael Lewis Kaplan ${ }^{2}$ and Yuh-Lang Lin ${ }^{1,3, *}$ \\ 1 Department of Physics, North Carolina A\&T State University, Greensboro, NC 27411, USA; \\ janising@gmail.com \\ 2 Applied Aviation Sciences Program, Embry-Riddle Aeronautical University, Prescott, AZ 86301, USA; \\ kaplanm1@erau.edu \\ 3 Applied Science \& Technology Ph.D. Program, North Carolina A\&T State University, \\ Greensboro, NC 27411, USA \\ * Correspondence: ylin@ncat.edu
}

check for updates

Citation: Ising, J.; Kaplan, M.L.; Lin, Y.-L. Effects of Density Current, Diurnal Heating, and Local Terrain on the Mesoscale Environment Conducive to the Yarnell Hill Fire. Atmosphere 2022, 13, 215. https:// doi.org/10.3390/atmos13020215

Academic Editor: Ilias Kavouras

Received: 15 December 2021

Accepted: 26 January 2022

Published: 28 January 2022

Publisher's Note: MDPI stays neutral with regard to jurisdictional claims in published maps and institutional affiliations.

Copyright: () 2022 by the authors Licensee MDPI, Basel, Switzerland. This article is an open access article distributed under the terms and conditions of the Creative Commons Attribution (CC BY) license (https:// creativecommons.org/licenses/by/ $4.0 /)$.

\begin{abstract}
The Yarnell Hill Fire, triggered by dry lightning on 28 June 2013, was initiated by hot and dry westerly winds, which rapidly shifted to north-northeast by convective-induced outflows. This sudden wind shift led to the demise of 19 firefighters. This study focuses on the environment and its predictive potential in terms of erratically changing the fire spread. Three numerical sensitivity tests are performed investigating the evolving synoptic-meso- $\beta$ scale environmental wind flow: (1) deactivating the evaporative cooling, (2) deactivating surface-driven diurnal heating/cooling, and (3) removing the mountain. Results show the strong north-northeasterly wind induced by the density current(s) and the diurnal surface sensible heating played the most significant roles in enhancing the mesoscale environment conducive to the rapid change in the fire spread direction. While the mountain played a less significant role in weakening the magnitude of the airflow affecting the fire, it still had an impact. Additionally, the Hot-Dry-Windy (HDW) index is calculated to determine its predictor role with respect to the atmosphere affecting the fire. The focus is not on feedback from explicit fire heating on the larger environment but rather the role of the environmental physical processes in causing the convectively induced rapid wind shifts.
\end{abstract}

Keywords: Yarnell Hill Fire; density current; diurnal heating; complex terrain; numerical modelling; Advanced Research Weather Research and Forecasting (WRF) model

\section{Introduction}

On Friday, 28 June 2013, a lightning strike from nearby convection triggered a small bush fire in west central Yavapai County, Arizona, just to the west of Yarnell, in a region known as the Yarnell Hills. A map of where Yarnell is located as shown in Figure 1.

On Sunday, 30 June 2013, during the early afternoon hours, convection built up between Flagstaff and Prescott. By mid-afternoon, this convection had developed into a northwest-southeast oriented squall line near Dewey-Humboldt $(\sim 20 \mathrm{~km}$ southeast of Prescott). The squall line generated a density current, which over the next hour, raced southwestward toward Yarnell. By about 1630 MST (2330Z), the density current arrived at the Yarnell Hills region and created a sudden shift in the fire direction from moving eastward, then to the south, and then southwestward (Figure 2 [1]). This sudden shift in the fire direction overcame and trapped 19 firefighters (Granite Mountain hotshots) battling the flame on the western front, which led to their unfortunate demise. The fire environment at the time was exceptionally hot and dry. Fire danger was high to extreme because of extreme drought conditions during the transition to the southwest monsoon summer season. During this seasonal transition, temperatures are typically hot. The relative 
humidity values remain low but fluctuate as storms become more numerous. The winds are highly variable with the highest wind speeds occurring during thunderstorms. These storms can generate strong downdrafts, microbursts, outflows, and gust fronts, all of which can affect fire behavior.
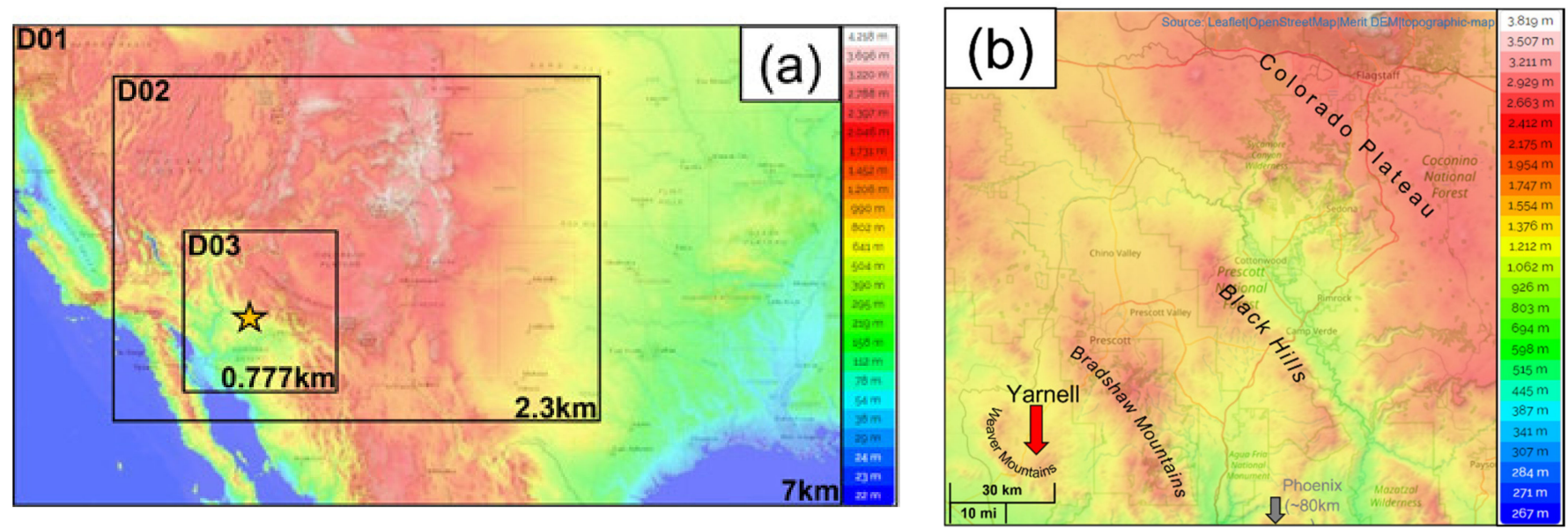

Figure 1. (a) Domain setup and (b) topographic features for CentralAZ, USA (sources: leaflet, topographic map). The star in (a) denotes the approximate location of Yarnell, AZ, USA.

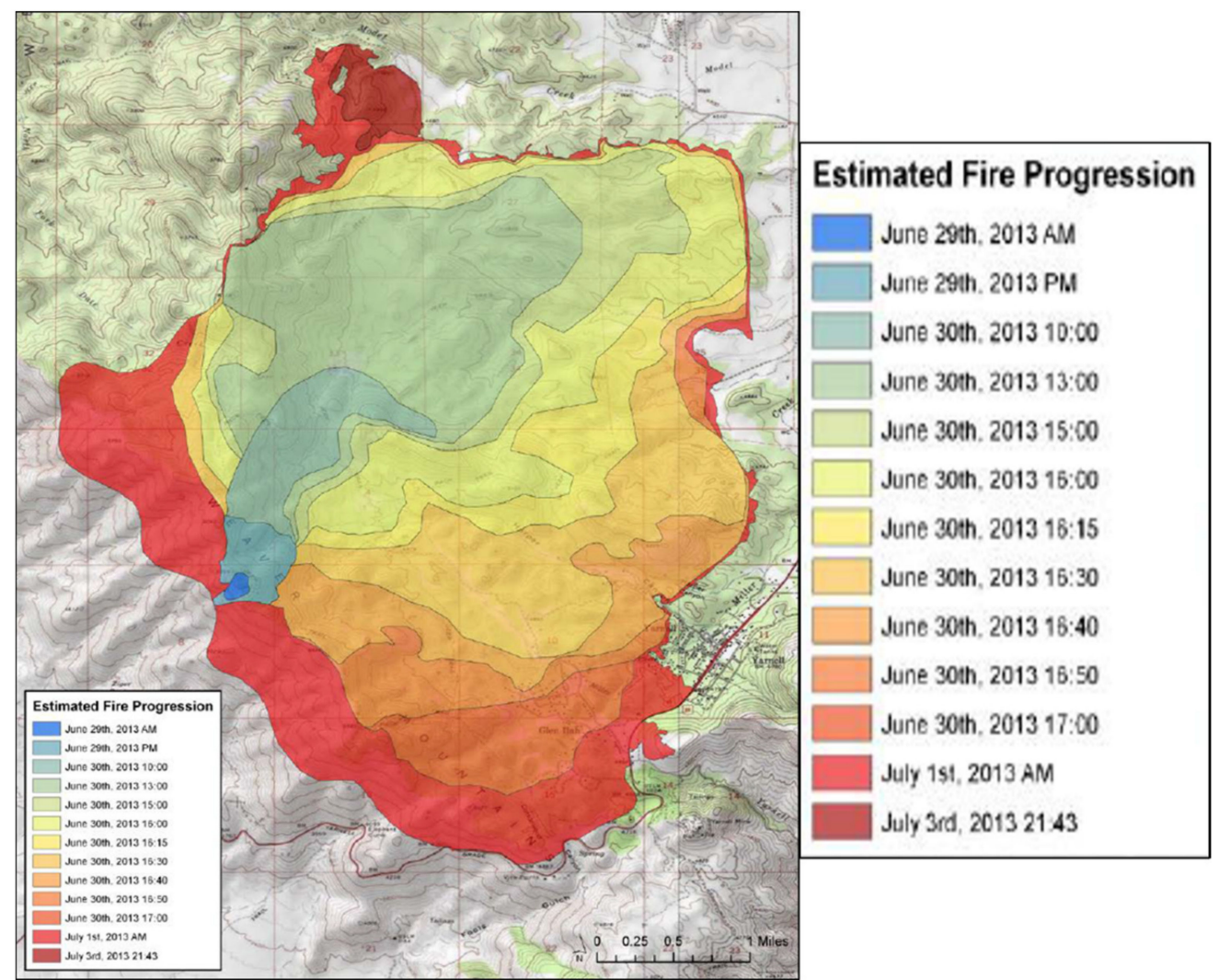

Figure 2. The estimated fire extent from 29 June to 3 July 2013. Darker colors represent fire spread during a later time. The color bar is enlarged in the right panel. (From the Yarnell Hill Fire Serious Accident Investigation Report, p. 81 [1]).

Wind affects fire by removing moisture from the air, igniting new fires through firebrand transport, and increasing oxygen supply. The biggest effect of wind is on the change in fire spread direction and rate [2] which many studies have examined [3-8]. Wind shifts affecting fire spread, such as in the Yarnell Hill Fire, were also observed in the Honey Fire 
that increased personnel risk and fire intensity [9], and in the Bass River Fire which led to fatalities [10]. Although not the focus in this study, synoptically induced severe downslope winds can affect fires near high elevations such as the Camp Fire [11], Witch Fire [12], and the Thomas Fire [13]. The numerical modeling in these studies has had mixed results when compared to observations. In the Dude Fire, model results closely resembled the observed fire behavior, and in the Waldo Canyon Fire, the gust fronts were simulated but the timing was $2 \mathrm{~h}$ too early. In the burn over incident at the St. Sebastian River Preserve and in the Bass River Fire, the weather forecasts and numerical modeling did not predict the wind accurately when compared to observations. In the Camp Fire, models performed decently with some surface observations. However, non-standardized practices led to poor performance with two commercial weather stations. These studies have indicated that the unpredictability and poor understanding of fundamental dynamical processes at the complex terrain scale of local wind strength and direction makes the numerical prediction of these winds and wind surges challenging, especially on small time scales as in the Yarnell Hill Fire. Thus, it is critical to study more fires where the wind played a vital role to improve fire weather prediction, create increased public safety, and reduce loss of life and property. Previous studies involving the Yarnell Hill Fire have not focused on the role of the environmental physical processes such as the density current generation and it is strengthening/weakening. There have been studies that investigated human factors such as the chain of error [14] and the decision-making process, communication, and dynamic flows of information, in which limitations of standard practices in the dangerous wildfire conditions were, discovered [15]. A study from the University of Berkley has also looked at the Yarnell Fire in part to determine whether fire station infrastructure is suitably placed such that areas of the highest wildfire risk are protected using a Geographic Information Systems approach [16].

Other studies have examined fire propagation and its complexity [17] and developed a novel model for fire evolution [18]. Neither study examined the thunderstorm outflow. Additional previous research on the Yarnell Hill Fire has focused on broader gust front characteristics through in situ observations with specific applications toward aviation [19]. This study found that wind speed, relative humidity, turbulent kinetic energy, and vertical motion increased while temperature decreased as the gust front passed. However, this study did not investigate the origins of the Yarnell gust front nor how the environment enhanced the Yarnell gust front, and its implications toward the fire shift (direction and intensity).

A recent observational study of the Yarnell case [20] analyzed the downscale organization of convection from the synoptic to meso-beta scale. However, our approach is unique because it employs model sensitivity studies at the meso-beta/gamma scale. Another study has researched cooling in a dry surface layer by looking at downdraft maximum available potential energy (DCAPE) and expanding this through a climatological analysis (seasonal and diurnal patterns) [21]. Finally, another recent study has led to the development and implementation of a software tool that identifies and depicts convective outflow boundaries in high-resolution numerical weather prediction models to provide guidance for fire weather forecasting [22]. For the DCAPE investigation, the focus is only on one aspect of the gust front and how it changes in the long term. For the software tool, while useful, the research does not directly investigate the outflow boundary interaction with other phenomena in complex terrain (like with the Yarnell Hill Fire) nor isolates the most important enhancement factors.

Prior research on Yarnell [17-22] has shown that the numerical prediction of wind surges remains challenging because of the lack of understanding of fundamental dynamical processes at the complex terrain scale. Improving the understanding of multi-scale atmospheric processes that control the motion and longevity of extreme fire events is vital. The study presented here will help answer questions such as: Which factors were the most important toward the density current generation and propagation? What impact, if any, did the isolated mountain to the southeast of Yarnell have on the density current direction 
and intensity? Can a fire index predict the change in the fire environment? Lastly, what role did evaporative cooling play?

Seldom has the Yarnell Hill Fire gust front, its origins, the strengthening/weakening factors, and the associated atmospheric processes been addressed in published literature. The research presented here focuses on filling this gap to better understand how the density current was organized by its environment, which includes the Yarnell Hill Fire.

A density current, or gravity current, is a region of dense fluid that moves into an environment of less dense fluid because of horizontal pressure gradient differences across a frontal surface [23]. In some cases, this density difference has been found to be smokeinduced [24]. There are different types of density currents that can exist depending on the environment. For example, density currents can occur with sea-breeze fronts [25], cold fronts [26], drylines [27], and can also be associated with an outflow from a thunderstorm [28,29]. Researchers have studied thunderstorm outflow density currents in-depth and have found bore-like disturbances [30,31] as well as solitary waves [32]. Others have looked at density currents in the scope of numerical modeling and have found that, for example, while shear decreases the horizontal convergence because of the downshearpropagating density current, it is nevertheless fundamental to the dynamical organization and depth of the density current [33]. Dynamical models have also been employed focusing on the role of stably stratified flow and cooling in density current organization and motion [34,35].

In the sense of affecting the fire environment, a density current is fundamentally different from a severe downslope wind event such as the Santa Ana winds in California. This wind event is generated by high pressure over the southwest U.S desert that flows westward toward a low pressure off the coast of California. Santa Ana winds increase wildfire risk from the dryness and speed of the winds, which are amplified and heated by downslope adiabatic heating along the coastal mountain lee slopes [36]. The time scale of the Santa Ana winds is on the order of days [37] and can be predicted up to a week in advance [38], whereas a density current is on the order of hours [39] and can only be predicted minutes to hours in advance as it relies on the parent thunderstorm stage [40].

In the Yarnell case, the density current moved from the northeast to the southwest into an environment with significant vertical wind direction shear. Near the fire, this created a sudden shift in wind direction and change in intensity (Figure 2). The wind changed from moving east to south, and then southwest and increased from $\sim 10$ to $\sim 20 \mathrm{~ms}^{-1}$. The density current changed the direction and speed of the wind ahead of it.

Diurnal surface sensible heating is an important factor for the generation of thunderstorms over land. Significant diurnal variations can be found globally, particularly over land and during summer. Thunderstorms occur much more often during the late afternoon over land in all seasons. This is because solar radiative heating during the day on the ground generates a late-afternoon maximum of convective available potential energy (CAPE) that is favorable for late-afternoon moist convection [41]. In July over Arizona, CAPE arises from a high moisture tongue that comes from either the Gulf of California, Mexico, or the Gulf of Mexico into the western United States, with maximum values in the late afternoon to early evening over much of the land area. The solar-driven cycle of surface pressure results in significant large-scale convergence over most of the western United States during the day, which includes Arizona. During the nighttime, the maximum thunderstorm activity occurs east of the Rockies, which is fueled by the eastward propagation of late afternoon thunderstorms generated in the west [42]. It is hypothesized that diurnal heating (in the context of this research, referring to the diurnal heat flux) plays one of the most significant roles in the generation of the thunderstorm, and in extension the outflow/density current, that rushed through Yarnell.

The North-Central Arizona terrain presents an excellent environment for studying atmospheric events [43]. The terrain around the Yarnell Hills is complex, consisting of small mountains, valleys, and plateaus. The Yarnell region is elevated and Yarnell sits within a terrain "bowl", surrounded to the west, south, and east by the Weaver Mountains. Yarnell 
sits at roughly $1400 \mathrm{~m}$ above mean sea level with the highest peak of the Weaver Mountains rising to $2000 \mathrm{~m}$, creating an elevation difference of about $600 \mathrm{~m}$. To the south immediately beyond the Weaver Mountains is an escarpment that drops $500 \mathrm{~m}$ (1400 m minus $900 \mathrm{~m}$ ) vertically over a horizontal distance of $3500 \mathrm{~m}$. Just beyond the Weaver Mountains to the east lies a northwest-southeast oriented valley at $1000 \mathrm{~m}$ above mean sea level. The terrain remains relatively flat toward the northeast up to the Bradshaw Mountains, and beyond lies the Verde Valley with an elevation minimum of about $1200 \mathrm{~m}$. The Verde Valley borders the Black Hills to the northeast and is followed by the Mogollon Rim, which forms the southern edge of the Colorado Plateau (Figure 1b).

Flow in and over complex terrain is multi-faceted. However, it has been found that surface flow characteristics are highly dependent on terrain slope, where the greatest difference in flow appears in regions behind the top of hills [44]. For example, for winds with larger flow/magnitudes, forcefully channeled strong ambient wind will lead to local winds almost perpendicular to the ambient winds. For winds with smaller flow/magnitudes, thermal effects drive local winds [45].

Additionally, thermo-topographic flows arise from differential heating [46] and affect wind through speed-up over ridges, flow channeling in valleys, flow separation around terrain obstacles [47], and generation of lee-side vortices parallel to mountain ridges [48].

An isolated mountain can have different effects on the ambient wind. Thermal variations create small-scale wind circulations such as a valley breeze during the day and a mountain breeze at night [49]. Additionally, wind increases with height and mountaintop winds are twice as high as surrounding low-altitude wind speeds [50]. Other effects include blocking [51] and strong downslope winds in the northern half of the lee of a ridge [52]. It is hypothesized that the role of complex terrain may aid in the divergence and blocking of local wind.

In the following sections, Section 2 will cover the model description and experimental design, which includes a discussion of the Hot-Dry-Windy index. Section 3 will present the observational analysis and model validation, simulated density current generation and propagation, effects of diurnal heating and evaporative cooling, effects of complex terrain, and density current interaction. Section 4 will conclude with a summary of the results and additional remarks including future work.

\section{Model Description and Experimental Design}

The Weather Research and Forecasting model version 4.0, which is also referred to as the WRF model in this study, is utilized for the numerical simulation sensitivity tests [53]. The initial and largest domain lateral boundary conditions employ the European Centre for Medium-Range Weather Forecasts Reanalysis 5 dataset (ERA5). ERA5 is available every hour for most variables and has global coverage with a spatial resolution of approximately $30 \mathrm{~km}$ and 137 vertical levels from the surface up to a height of $80 \mathrm{~km} \mathrm{[54].} \mathrm{Data} \mathrm{are}$ available from January 1, 1979, to the present date at the time of this writing.

The domain was set up with a 3:1 ratio on a Lambert Conformal Map projection starting at a horizontal resolution of $7 \times 7 \mathrm{~km}$ as the outermost domain (D01), then $2.3 \times 2.3 \mathrm{~km}$ as domain 2 (D02), and $0.777 \times 0.777 \mathrm{~km}$ as domain 3 (D03), as shown in Figure 1a. D01 extends from California to Arkansas and from Wyoming to Texas. D02 extends from approximately Baja California to Central Texas and Utah to Central Texas. D03 covers most of the state of Arizona and is approximately centered over the Yarnell Hill Fire. D01 and D02 were extended toward the north and east of Arizona to capture the synoptic setup to allow for spin-up time and to capture the convection passing through the lateral boundaries. D01 starts on 29 June 2013, 1700 MST (30 June 2013, at 0000Z), and ends on 30 June 1700 MST (1 July 2013, at 0000Z), since that was when the Yarnell Hill Fire incident occurred. Each subsequent domain starts and ends on the same days but at later start times (0500 MST/1200Z for D02 and 0800 MST/1500Z for D03) and the same end time. Table 1 summarizes the domain start/end times. For the vertical resolution, 50 stretched levels were used on all domains. Land use data are taken at 5 arcminutes (D01), 
2 arcminutes (D02), and 30 arcseconds (D03) from the MODIS IGBP 21-category dataset. In meters, 5 arcminutes is about $7600 \mathrm{~m}, 2$ arcminutes is about $3000 \mathrm{~m}$, and 30 arcseconds is about $760 \mathrm{~m}$, for a latitude of $34.22^{\circ} \mathrm{N}$ (Yarnell, AZ, USA). Output is written every $4 \mathrm{~h}$ (D01), $1 \mathrm{~h}$ (D02), and $15 \mathrm{~min}$ (D03).

Table 1. Domain structure, grid resolution, extents, and runtimes.

\begin{tabular}{|c|c|c|c|c|}
\hline Domain & $\begin{array}{l}\text { Grid Points }(x, y) \\
\text { Grid Resolutions }\end{array}$ & $\begin{array}{c}\text { Extent } \\
{[\mathrm{W}, \mathrm{E}] \times[\mathrm{S}, \mathrm{N}]}\end{array}$ & $\begin{array}{c}\text { Start } \\
\text { YYYYMMDD UTC }\end{array}$ & $\begin{array}{c}\text { End } \\
\text { YYYYMMDD UTC }\end{array}$ \\
\hline 1 & $\begin{array}{c}409 \times 277 \\
7 \mathrm{~km} \times 7 \mathrm{~km}\end{array}$ & {$\left[121^{\circ} \mathrm{W}, 89^{\circ} \mathrm{W}\right] \times\left[26^{\circ} \mathrm{N}, 43^{\circ} \mathrm{N}\right]$} & $\begin{array}{c}\text { 2013-06-30 } \\
0000 Z\end{array}$ & $\begin{array}{c}\text { 2013-07-01 } \\
0000 Z\end{array}$ \\
\hline 2 & $\begin{aligned} 718 & \times 544 \\
2.3 \mathrm{~km} & \times 2.3 \mathrm{~km}\end{aligned}$ & {$\left[116^{\circ} \mathrm{W}, 99^{\circ} \mathrm{W}\right] \times\left[29^{\circ} \mathrm{N}, 40^{\circ} \mathrm{N}\right]$} & $\begin{array}{l}2013-06-30 \\
1200 Z\end{array}$ & $\begin{array}{c}2013-07-01 \\
0000 Z\end{array}$ \\
\hline 3 & $\begin{aligned} 730 & \times 742 \\
0.777 \mathrm{~km} & \times 0.777 \mathrm{~km}\end{aligned}$ & {$\left[114^{\circ} \mathrm{W}, 109^{\circ} \mathrm{W}\right] \times\left[31^{\circ} \mathrm{N}, 36^{\circ} \mathrm{N}\right]$} & $\begin{array}{l}2013-06-30 \\
1500 Z\end{array}$ & $\begin{array}{l}\text { 2013-07-01 } \\
\text { 0000Z }\end{array}$ \\
\hline
\end{tabular}

The most important reason to employ the WRF with initialized, complete threedimensional atmospheric structure is that the space-time continuity of the density current and supporting convection are resolved. Idealized modeling would likely miss key details of the horizontal variation of convection and its effects on density current organization and motion. Higher resolution simulations would benefit from employing the LES formulation to better resolve the structure of planetary boundary layer eddies that affect convective initiation and maintenance in the complex terrain.

Four simulations including three sensitivity tests were conducted to examine the density current generation, propagation, and interaction through the complex terrain. Initially, a control case (CNTL) was run for comparison, then the southeast Weaver Mountain (NSEM) was removed to study the blocking effects. Afterward, evaporative cooling was turned off (NEVP) to investigate the importance of latent heat change effects. Finally, the last sensitivity test involved turning off the diurnal surface sensible heating to examine the importance of convective instability building during the day (NDHT).

For the CNTL case, the microphysics used was the Purdue Lin scheme [55]. For the surface, land-surface, and boundary layer physics schemes, the physics parameterizations were set to the Eta Similarity scheme [56-59], unified Noah land-surface model [60], and Mellor-Yamada-Janjic (Eta) TKE [57,61]. The cumulus parameterization was set to the Grell-Freitas ensemble scheme [62] only for the outermost domain (D01) since this scheme is scale sensitive for a horizontal domain resolution of $7 \mathrm{~km}$. For all other domains, no cumulus parameterization scheme was used. These schemes are summarized in Table 2. These physics, in general, were chosen to include parameterizations that are not too computationally expensive but still representative for the convection and the wind event. The Purdue-Lin scheme was chosen because it is a five-class microphysics scheme that includes graupel and because of its ability to handle high-resolution domains. The Eta Similarity scheme was chosen because of the choice for the boundary layer physics scheme (paired), the unified Noah land-surface model because of its sophisticated vegetation modeling, and the Mellor-Yamada-Janjic (Eta) TKE scheme for its ability to handle thin layers. In the NSEM case, the only change was flattening the terrain of the isolated Weaver Mountain to that of the surrounding terrain (Figure 3b). For the NEVP case, the evaporative cooling was turned off in the Lin microphysics module (to turn off the reset of potential temperature) and within the moist physics subroutine in the long time step utility code. Finally, for the NDHT case, the surface layer and boundary layer physics schemes were turned off. The following sections will focus on the results from D03, not from the ERA5 reanalysis, which is the initializing dataset. 
Table 2. Physics parameterization schemes for the sensitivity tests.

\begin{tabular}{cc}
\hline Physics Parameterization & Scheme \\
\hline Cumulus (only on Domain 1) & Grell-Freitas Ensemble \\
\hline Microphysics & Purdue-Lin \\
\hline Planetary Boundary Layer & Mellor-Yamada-Janjic (Eta) TKE \\
\hline Surface Layer & Monin-Obukhov (Janjic Eta) \\
\hline Land Surface & Unified Noah Land Surface Model \\
\hline Longwave Radiation (every 7 min) & RRTM \\
\hline Shortwave Radiation (every 7 min) & Dudhia Shortwave \\
\hline
\end{tabular}

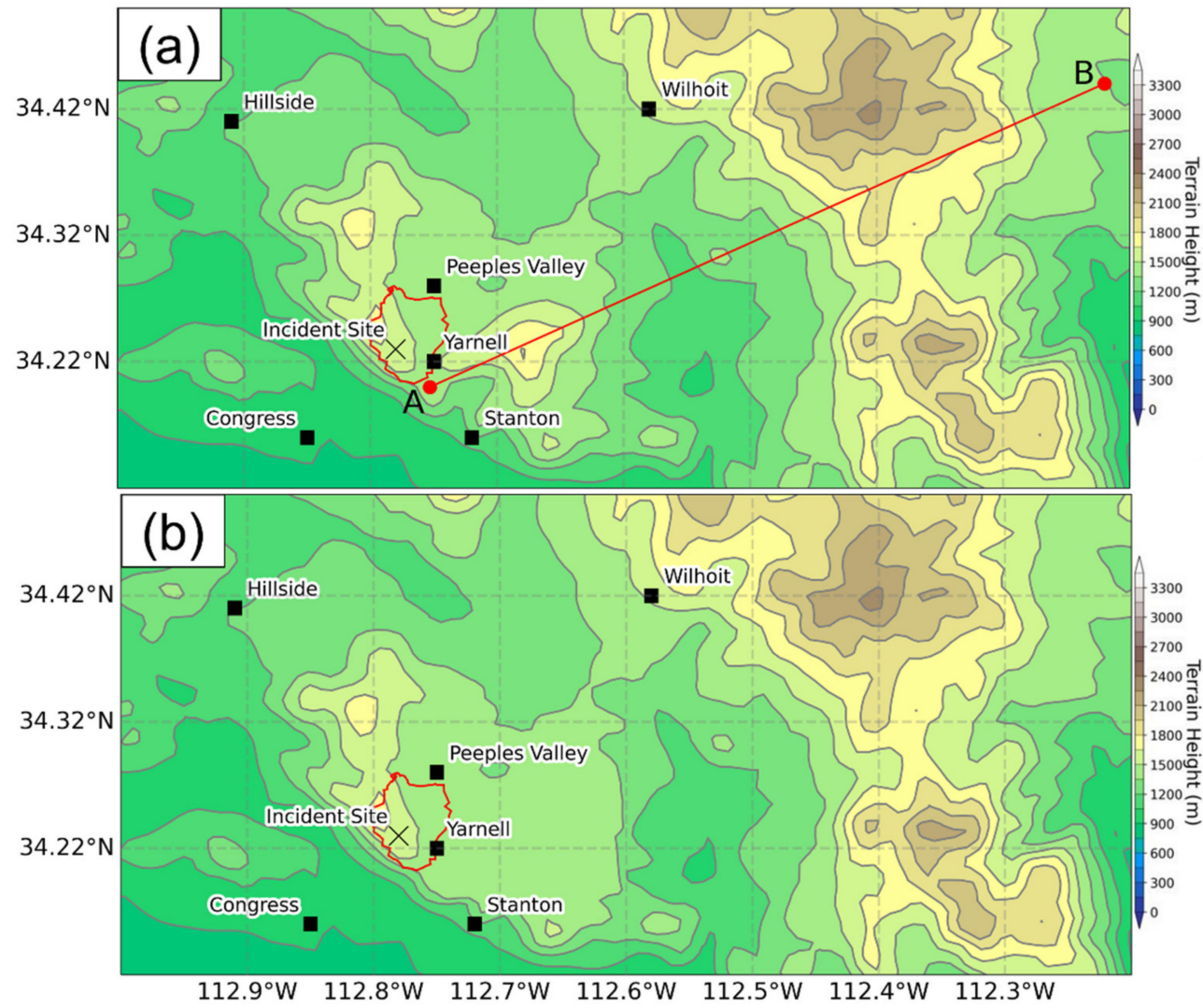

Figure 3. Terrain removal for the NSEM Mountain case: (a) the original terrain in the CNTL case and (b) the southeast Weaver Mountain flattened to approximately $1400 \mathrm{~m}$, which is the elevation of the surrounding terrain toward the north and west. The contours represent the elevation. Black squares are cities for spatial references (see names in the figure). The higher elevations toward the top and right of the figure are the Bradshaw Mountains. The red straight line in panel (a) is for the cross-section used for cases CNTL and NSEM, such as in Figures 17 and 18 later.

\section{The Hot-Dry-Windy (HDW) Index}

Historically, fire prediction has been formulated with the lower atmosphere severity index, also called the Haines Index [63]. The Haines Index is a fire index that computes the potential for wildfire based on the sum of a stability and a dryness term on a scale of 1-6. There are three variants of the Haines Index, a low, medium, and high variant. Despite its popularity, the Haines Index has been found to be problematic because it does not account for the wind factor which is often vital to any wildfire growth [64]. A new index, the one used in this study, has recently been formulated called the Hot-Dry-Windy Index (HDW) that predicts the potential for fire using temperature, moisture, and wind, three parameters that are much more relevant to wildfire spread and growth [65]. Srock et al. (2018) describe 
an operational variant of the HDW called the HDWI as well, where the "I" stands for index. The HDWI uses the Climate Forecast System Reanalysis (CFSR) as input data, which are provided at a lower spatial and temporal resolution than the ERA-5 dataset. Because of the lower resolutions, HDWI, as discussed in Srock et al. (2018), is not appropriate for predicting fine-scale weather (such as density currents) to affect fire behavior. Here, HDW is presented from the raw formulation rather than from the operational variant (HDWI) and for some theory and background. HDW Equation (1) is defined as per below:

$$
\begin{gathered}
H D W=U \times \operatorname{VPD}(T, q) \\
\operatorname{VPD}(T, q)=e_{S}(T)-e(q) \\
e_{s}=6.11 \times \exp \left[\frac{L_{V}}{R_{v}}\left(\frac{1}{273.15 K}-\frac{1}{T}\right)\right] \\
e(q)=R H(T, q) \times \frac{e_{s}(T)}{100 \%}
\end{gathered}
$$

In Equation (1), HDW is the product of the horizontal wind $(\boldsymbol{U})$ and the vapor pressure deficiency $(V P D)$ as a function of the temperature $(T)$ in Kelvin and the mixing ratio $(q)$. The VPD Equation (2) is the difference between the saturated vapor pressure $\left(e_{s}\right)$ and the vapor pressure $(e)$, where $e_{s}$ and $e$ are measured in hectopascals $(\mathrm{hPa})$. To obtain the saturated vapor pressure, the Clausius-Clapeyron Equation (3) can be used. Here, $L_{V}$ and $\boldsymbol{R}_{V}$ are the latent heat of vaporization at $0{ }^{\circ} \mathrm{C}$ and the gas constant for water vapor and have constant values of $2.5 \times 10^{6} \mathrm{~J} \mathrm{~kg}^{-1}$ and $461 \mathrm{~J} \mathrm{~K}^{-1} \mathrm{~kg}^{-1}$, respectively. To obtain the vapor pressure, the relative humidity $(\boldsymbol{R H})$ is multiplied by the saturated vapor pressure, Equation (4). HDW is measured in hundreds and is nondimensional, where 100 is low and 800 is considered high. The interpolation of HDW is performed at $830 \mathrm{hPa}$ as this level is closest to the ground without intersecting the ground (or a significant portion of mountains).

HDW has been proven effective for fires such as the Pagami Fire where HDW identified the specific day on which the fire was most difficult to manage, the Bastrop Fire where HDW identified days where an initiating fire may spread rapidly because of large-scale weather conditions, and the Double Trouble Fire where HDW identified days where fires can become difficult to manage [65]. Climatologically, HDW provides insight into nearsurface climatic conditions which can be used to determine temperature and humidity trends related to climate classification systems [66]. This study will also attempt to examine the fire predictability for the Yarnell Hill Fire using HDW, not the HDWI formulation.

\section{Results}

This section will begin with an analysis of the general environment and radar for 30 June 2013, the day of the Yarnell Hill Fire incident, and a comparison to the CNTL case with justification. Afterward, an explanation of the initial density current generation and propagation will be presented. Then, an analysis of the NDHT, NEVP, and NSEM cases. The section will finish with an overview of HDW during the event for the CNTL simulation and a comparison to observations at Peeples Valley and Stanton, AZ, USA (employed to calculate HDW). Finally, a comparison will be performed between the simulated wind magnitude, wind direction, and the simulated relative humidity for the CNTL case, and the observed surface wind magnitude, wind direction, and relative humidity at Cherry, Peeples Valley, and Stanton, AZ, USA.

\subsection{Observational Analysis and Model Validation}

Figure 4 shows the observed and simulated soundings for the CNTL case at Flagstaff on 06/30/13 at 1700 MST (07/01/13, at 0000Z). The surface temperatures and dew points are in general agreement and show as approximately 25 and $2{ }^{\circ} \mathrm{C}$, respectively. In the midtroposphere, the soundings are in some disagreement. Specifically, the simulated sounding 
shows a slightly more saturated environment. Similarly, in the upper troposphere, the inversion found in the observed sounding is smaller than in the simulated sounding. Winds were also generally in agreement throughout the sounding. Overall, the soundings are similar and thus the simulation is representative of the observed environment.

Flagstaff 07/01/13 00:00Z

(17:00 MST)

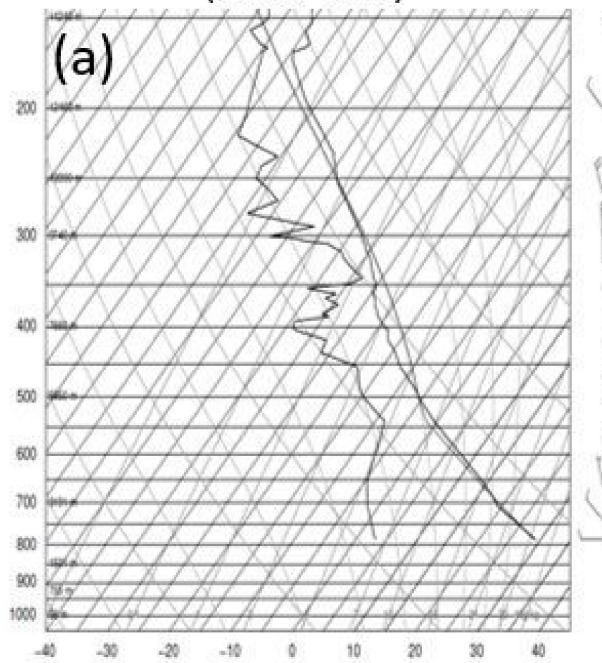

Flagstaff 06/30/13 17:00 MST

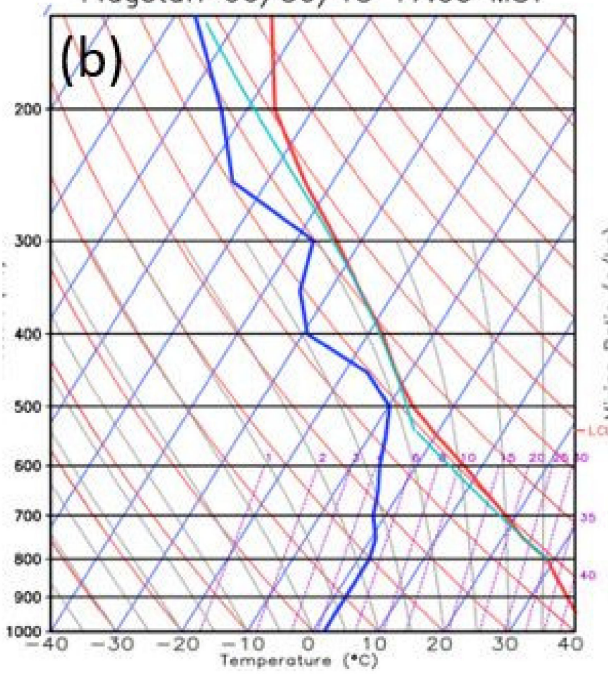

SLAT 35.23

SLON $=111.82$

SELV 2192 .

SHOW -9999

LIFT 0.06

SWET -9999

CINX -999

TOT -9999

TOTL -9999

CAPE 2674

CAPV 308.5

CINS -79.8

CINV -52.3

EOLV 249.2

EQTV 248.

LFCT 495.7

LFCV 506.8

BRCH 9.15

BRCV 10.56

LCLT 269.9

LCLF 329.9

MLTH 323.6

MLMR 5.76

THCK 5694

THCK 5694
PWAT 15.15

Figure 4. Skew-T sounding for Flagstaff, 30 June 20131700 MST (01 July 2013, at 0000Z). (a) Observed (source: UWYO, upper air soundings) and (b) CNTL simulated soundings with extrapolation to $1000 \mathrm{mb}$.

During the morning and early afternoon hours on 30 June 2013, there was scattered, generally unorganized, and localized convection over the center-west portion of Arizona, stretching from Yarnell to just southwest of Sedona with a focus near Sedona (Figure 5). Throughout the afternoon (Figure 6), the environment became more conducive to organized convection as temperatures began to rise and moisture was transported from the east and north. Both Figures 5 and 6 show the reflectivity mosaic from NCEI on 30 June. By 1315 MST/2015Z, a small cell (Figure 6a, red circle) had developed west of Cherry, AZ, USA (by the Black Hills (note Figure 1)) and North of Dewey, AZ, USA. This served as the anchor point for later convection resulting from the air that was likely lifted by the MountainPlains Solenoid (MPS) circulation over the Black Hills that created the first ensemble of density currents. The cell remained relatively stationary and reached its maximum 
reflectivity ( 50 dBZ) within 25 min. By 1400 MST (2100Z), a small-scale squall line had developed around the periphery, oriented northwest to southeast from Prescott Valley to just east of Interstate 17, and began to propagate toward the southwest. By 1500 MST, the squall line rapidly intensified as convection fired along the northwest and southeast sides stretching from Paulden, AZ, USA, to Pine, AZ, USA. The environment toward the northwest remained favorable for convection while the environment toward the center of the squall line remained less conducive to convection. By 1545 MST (2245Z), the squall line had become wider toward the northwest and began its transition past peak intensity and into stratiform precipitation. By 1645 MST, the entire system has transitioned to stratiform precipitation as it moved over the Yarnell Hill area.

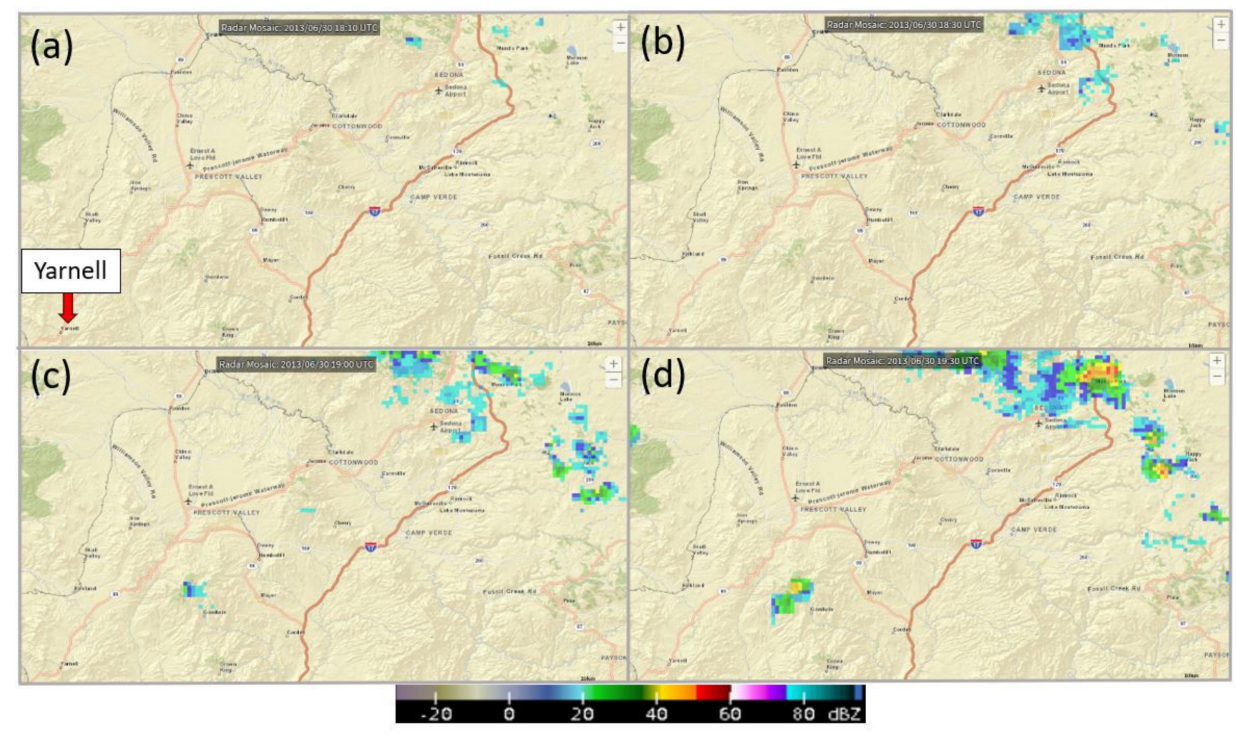

Figure 5. Scattered observed reflectivity mosaic from KFLX (Flagstaff, AZ, USA) 30 June 2013: (a) 1110, (b) 1130, (c) 1200, and (d) 1230 MST (source: NCEI GIS Map Portal).

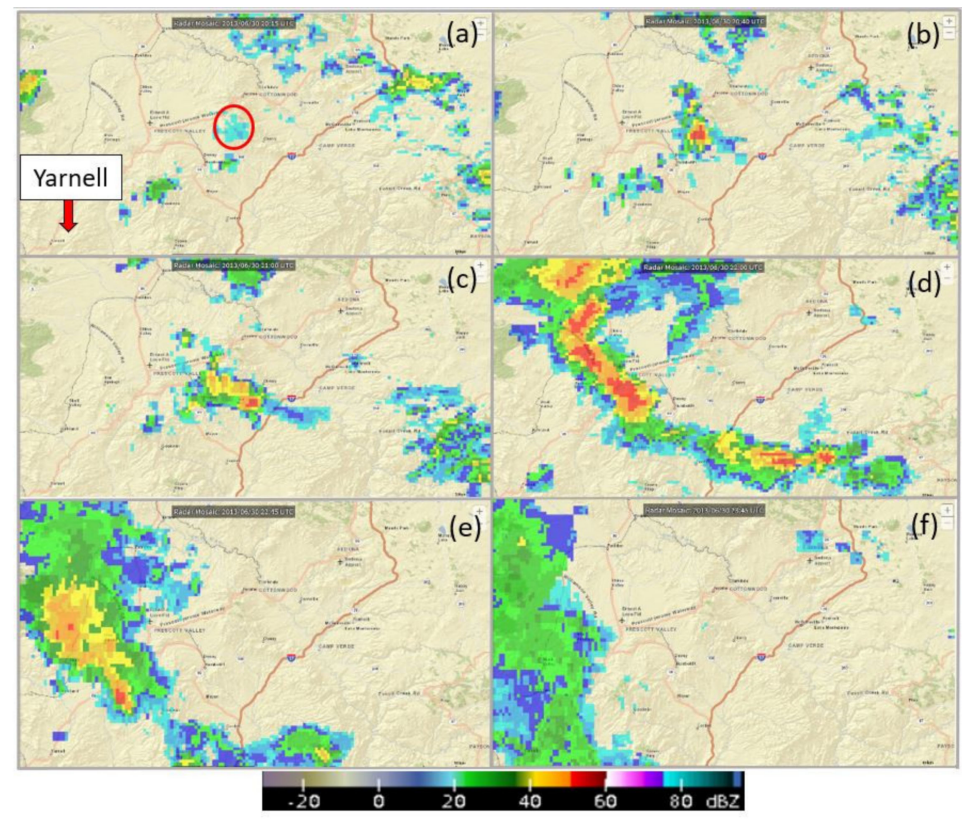

Figure 6. Observed reflectivity mosaic from KFLX (Flagstaff, AZ, USA) 30 June 2013: (a) 1315, (b) 1340, (c) 1400, (d) 1500, (e) 1515, and (f) 1645 MST (source: NCEI GIS Map Portal). The red circle in (a) denotes a small cell that had developed west of Cherry, AZ, USA, and North of Dewey, AZ, USA, around 1315 MST (source: NCEI GIS Map Portal). 
Comparing the observed radar to the CNTL case shows that the simulation is similar in convective structure, timing, and location (Figure 7). In the CNTL case, by 1315 MST, there is convection toward the northeastern part of the domain, which is slightly more widespread than in the observations, with the convection extending slightly further toward the northwest and southeast. The squall line begins around the same time (1315 MST) and place (west of Cherry and north of Dewey-Humboldt) but is significantly stronger in the simulation. The squall line fully developed similarly in the simulation to the observed radar, at 1500 MST. However, the simulated squall line appears to be more northwest biased and does not initiate toward the south and east of Yarnell as in the observations. A transition into stratiform precipitation is seen later toward the end of the simulation starting at 1645 MST. Overall, the convection initialization and location for the analysis are generally in agreement but the buildup and break down time to maximum intensity and stratiform precipitation, respectively, take longer to reach in the CNTL simulation. Comparing the reflectivity at $1315 \mathrm{MST}, 5 \mathrm{dBZ}$ is depicted in the observed vs. nearly $40 \mathrm{dBZ}$ in the simulation at the location where the squall line develops. About $30 \mathrm{~min}$ later, $50 \mathrm{dBZ}$ is depicted in the observations vs. nearly $40 \mathrm{dBZ}$ in the simulation, which is more inline. Since the CNTL case and the observations are generally in agreement, the analysis was conducted based on the input parameters from the CNTL case and the simulation modifications made where appropriate and are described more lately. It should be noted that, in the observations, the nearest weather radar is Flagstaff (KFLX), which is about $150 \mathrm{~km}$ toward the northeast, outside of the domain. The simulation depicts the maximum vertical column reflectivity, thus what the radar sees may not necessarily be the maximum reflectivity in the vertical column because of the beam angle by the time it reaches Yavapai County.
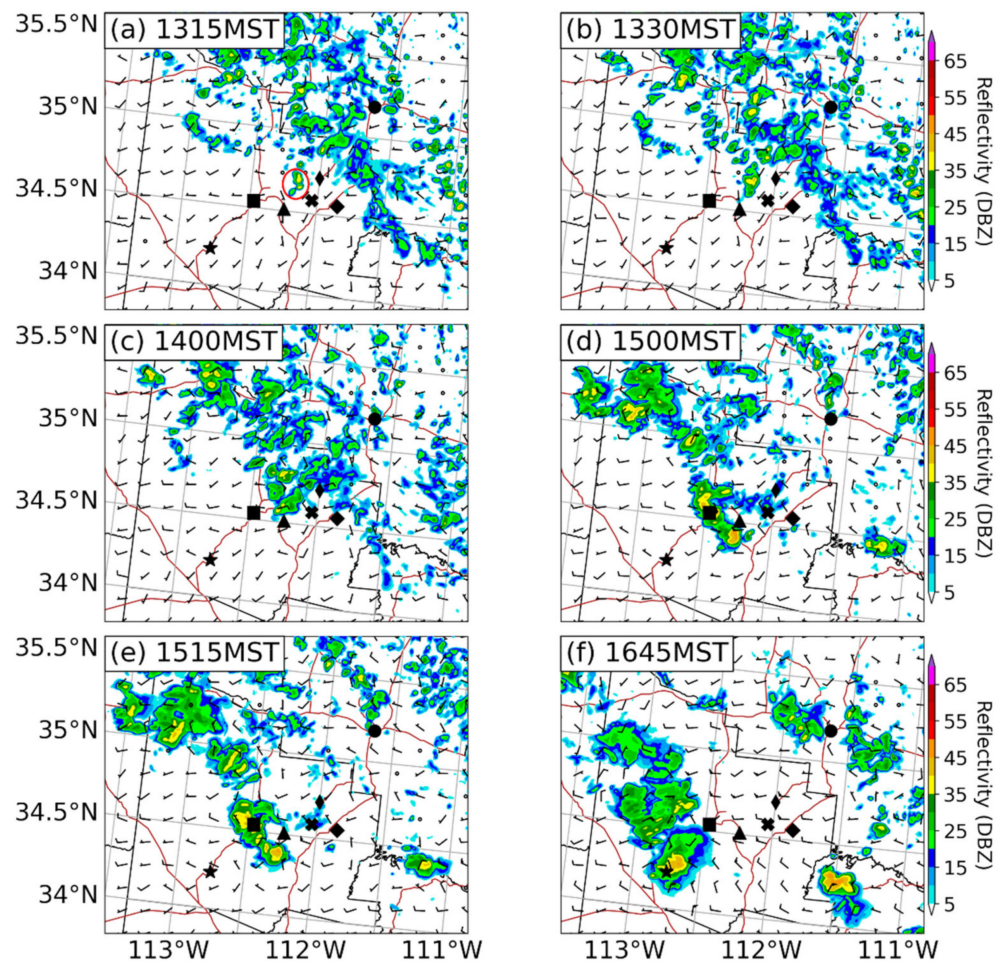

Figure 7. CNTL case simulated maximum column reflectivity and $10 \mathrm{~m}$ horizontal wind on 06/30/13: (a) 1315, (b) 1330, (c) 1400, (d) 1500, (e) 1515, and (f) 1645 MST. The red circle in (a) denotes a small cell that had developed west of Cherry, AZ, USA, and North of Dewey, AZ, USA, around 1315 MST. The symbols in the figure denote the following locations: Yarnell (star), Prescott (square), Dewey-Humboldt (triangle), Cherry (x), Camp Verde (diamond), Cottonwood (narrow diamond), and Flagstaff (circle). Yavapai County is enclosed by the thin black line, the major roads are denoted by the red lines, and the latitude/longitude grid lines are denoted by the light gray straight lines. 
Figure 8 shows the simulated reflectivity between the CNTL and NEVP cases. From before, the CNTL case (a-b) agrees rather well with the observed reflectivity. In the simulation, the convection that initialized over the Black Hills is present but slightly further toward the north by 1300 MST (2000Z). By 1400 MST, the convection develops into a small squall line that is oriented northwest to the southeast that propagates southwestwards where the intensity is slightly less than what was observed. For the NEVP case, the convection initialization over the Black Hills is also seen at 1300 MST with a slight offset toward the north. However, the convection remains stationary and does not intensify by 1400 MST. In the NDHT case (not shown), little/no convection is present in either time since there is no surface sensible heating. There is only a small patch of extremely localized weak convection toward the eastern part of the domain, which results from other diabatic heating processes.
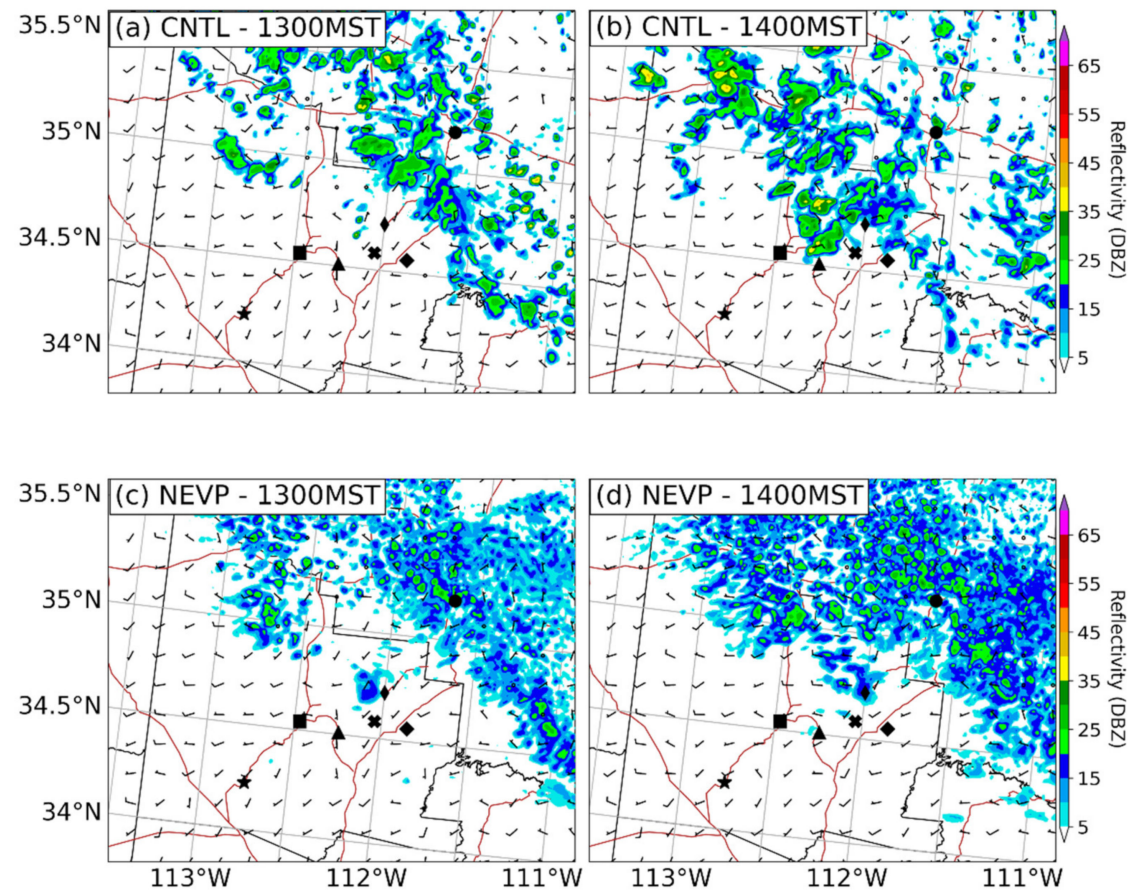

Figure 8. Convection initiation in cases CNTL and NEVP at 1300 and 1400 MST. The symbols in the figure denote the following locations: Yarnell (star), Prescott (square), Dewey-Humboldt (triangle), Cherry (x), Camp Verde (diamond), Cottonwood (narrow diamond), and Flagstaff (circle). The black outline is Yavapai County and red lines are major roads. The light gray straight lines indicate latitude and longitude grid lines.

The Yarnell Hill environment on 30 June 2013 was exceptionally hot and dry with temperatures near 100 degrees Fahrenheit and relative humidity below 30\% (in most cases, well below). Table 3 shows the surface observations at Cherry, Peeples Valley (about $6 \mathrm{~km}$ to the north-northwest of Yarnell), and Stanton, AZ, USA (about $6 \mathrm{~km}$ to the southeast of Yarnell). The squall line that generated the density current that rushed through the Yarnell Hill Fire developed to the southwest of Cherry and propagated southwestward. The observed wind surge in Cherry is a weaker component of the density current that propagated northeastward. The portion of the density current toward the southwest propagated first through Peeples Valley at a velocity of nearly $8 \mathrm{~ms}^{-1}$ during the late afternoon and then through Yarnell and Stanton shortly after at a velocity of nearly $13 \mathrm{~ms}^{-1}$, according to the observed data. The passage of the density current is noted by an increase in wind speed, shift in wind direction, drop in temperatures, and an increase in relative humidity. How the simulated results compared to the observations will be evaluated at the end of this section. The next subsection will explore the density current and the role of the MPS, which explains the location and intensity of the convection over the Black Hills. 
Table 3. Surface observations at Cherry, Peeples Valley, and Stanton, AZ, USA, during the mid to late afternoon on 30 June $2013[1,67]$. The passage of the density current is depicted by the bolded text.

\begin{tabular}{|c|c|c|c|c|c|c|c|c|c|c|c|}
\hline \multicolumn{6}{|c|}{ Stanton $06 / 30 / 13$} & \multicolumn{6}{|c|}{ Peeples Valley 06/30/13 } \\
\hline Time & Temp. & R.H. & Wind & Dir. & Wind & Time & Temp. & R.H. & Wind & Dir. & Wind \\
\hline (MST) & (Deg. F) & $(\%)$ & (mph) & (deg.) & (card.) & (MST) & (deg. F) & $(\%)$ & (mph) & (Deg.) & (card.) \\
\hline $15: 01$ & 102.99 & 14 & 8.99 & 212 & SSW & $15: 09$ & 96.03 & 15 & 10.98 & 244 & WSW \\
\hline $16: 01$ & 102.99 & 14 & 13 & 216 & SW & $15: 24$ & 97.02 & 14 & 13.00 & 215 & SW \\
\hline $17: 01$ & 95 & 17 & 25.99 & 20 & NNE & $15: 39$ & 96.03 & 15 & 13.00 & 250 & WSW \\
\hline 18:01 & 95 & 15 & 22.01 & 16 & NNE & $15: 54$ & 95.02 & 15 & 5.99 & 253 & WSW \\
\hline \multirow[t]{5}{*}{ 19:01 } & 97 & 12 & 4 & 16 & NNE & $16: 09$ & 94.03 & 16 & 8.01 & 259 & $\mathrm{~W}$ \\
\hline & & & & & & $16: 24$ & 93.02 & 17 & 4.99 & 341 & NNW \\
\hline & & & & & & $16: 39$ & 89.02 & 23 & 8.01 & 44 & $\mathrm{NE}$ \\
\hline & & & & & & $16: 54$ & 85.03 & 26 & 10.98 & 28 & NNE \\
\hline & \multicolumn{5}{|c|}{ Cherry 06/30/13 } & $17: 09$ & 85.03 & 26 & 10.98 & 27 & NNE \\
\hline Time & Temp. & R.H. & Wind & Dir. & Wind & $17: 25$ & 85.03 & 22 & 17.98 & 59 & ENE \\
\hline (MST) & (Deg. F) & $(\%)$ & (mph) & (deg.) & (card.) & $17: 41$ & 87.03 & 20 & 14.99 & 9 & $\mathbf{N}$ \\
\hline $15: 01$ & 88 & 21 & 4 & 346 & NNW & $18: 02$ & 87.03 & 19 & 8.01 & 355 & $\mathrm{~N}$ \\
\hline 16:01 & 88 & 20 & 11 & 285 & WNW & $18: 25$ & 90.01 & 14 & 3.00 & 339 & NNW \\
\hline $17: 01$ & 88 & 21 & 11 & 304 & WNW & $18: 40$ & 91.02 & 13 & 5.99 & 247 & SWS \\
\hline 18:01 & 86 & 16 & 9 & 305 & WNW & $18: 55$ & 90.01 & 14 & 8.99 & 273 & $\mathrm{~W}$ \\
\hline 19:01 & 87 & 16 & 7 & 90 & $\mathrm{E}$ & $19: 10$ & 90.01 & 14 & 4.99 & 74 & ENE \\
\hline
\end{tabular}

\subsection{Simulated Density Current Generation and Propagation}

Since the convection propagation was from the northeast toward the southwest on 30 June 2013, a cross-section parallel to this direction can be defined. Cross-section $\mathrm{H}$ (Figure 9) is used and extends just west-southwest of Yarnell, AZ, USA, northeastwards to the Black Hills. For the MPS discussion, the cross-section is extended by about $20 \mathrm{~km}$ to the northeast to cover more of the Black Hills.

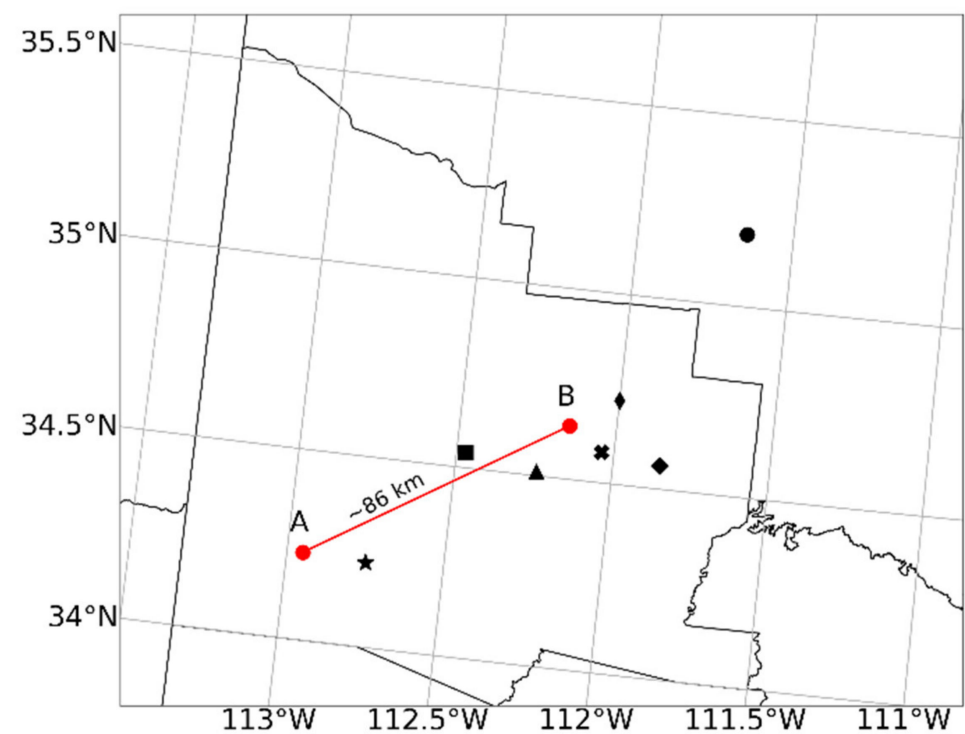

Figure 9. Cross-sections H over Yavapai County. The symbols in the figure denote the following locations: Yarnell (star), Prescott (square), Dewey-Humboldt (triangle), Cherry (x), Camp Verde (diamond), Cottonwood (narrow diamond), and Flagstaff (circle). The black outlines are county outlines, with the most prominent outline being Yavapai County. The light gray straight lines indicate latitude and longitude grid lines.

The formation of the density current is initialized from convection over the Black Hills. This convection is triggered by an MPS circulation that develops during the late morning in the CNTL simulation (Figure 10). From the left column of Figure 10 (panels a, c, and e), around 1000 MST, a cold pocket is present on the lee side of the Black Hills which is 
seen from the expanded isentropes. The cold pocket reaches from the bottom of the Verde Valley to the peak of the Black Hills in the cross-section. The origin of the cold pocket arises from a katabatic jet flow down the northeastern slope accompanying a nocturnal jet. When the sun rises, this nocturnal jet begins to slow which produces convergence that lifts the cold air, creating a stable core. After sunrise, the nocturnal katabatic flow is replaced by a mesoscale solenoidal circulation, in this case by 1000 MST, which is seen by the faint up/down vertical velocity couplet anchored to the lee slope. Upslope flow is produced from the horizontal pressure gradient force toward the slope because of the buoyancy associated with the surface sensible heating. The main upward flow is in a narrow zone above the slope, known as the leeside convergence zone (LCZ). The LCZ acts to lift air, which creates a cold core (upward kink in isentropes on the lee slope of Black Hills). This lifted air advects additional moisture into the atmosphere that provides the fuel for the convection that forms in the early afternoon which subsequently generates the density current resulting from evaporative cooling by the precipitation downdraft.
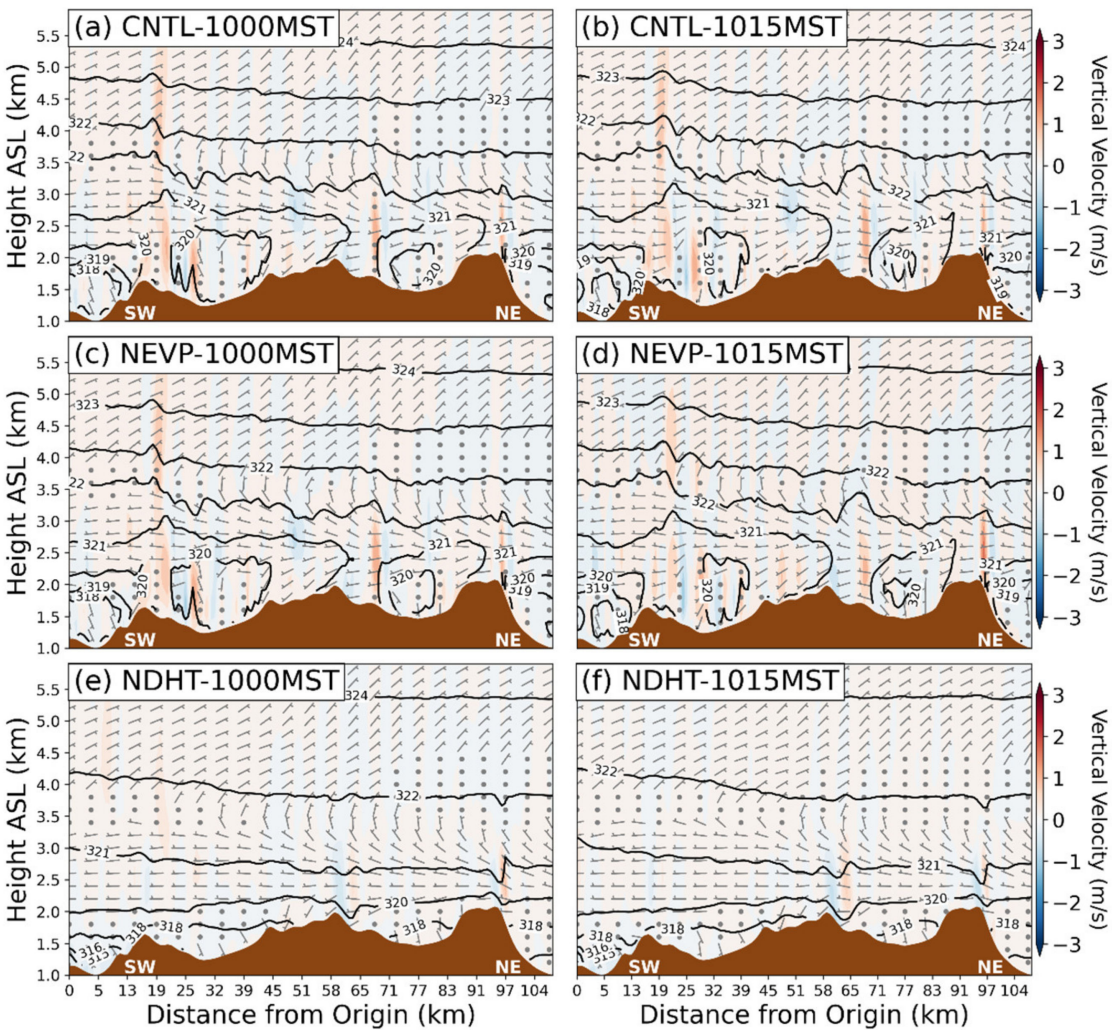

Figure 10. MPS signature over the Black Hills (mountains on the far-right side of the cross-section) for cases CNTL (a,b), NEVP (c,d), and NHDT (e,f), at 1000 MST (a,c,e) and 1015 MST (b,d,f). The wind barbs depict horizontal wind, the black contours potential temperature, and the shaded color shows vertical velocity. The cross-section is defined in Figure 9 and goes left to right (SW to NE).

During the initiation of convection in the early afternoon, the density current (henceforth denoted as D0) propagated southwestwards from the Mogollon Rim through the Verde Valley and approached the Black Hills. D0 encountered the region of MPS-initiated convection developing southeastwards along the Black Hills. The convection strengthened and radiated three additional density currents that emanated around the periphery of the Black Hills, denoted D1a, D1b, and D1c. D1a propagated northeastwards back toward the northwestern Verde Valley, D1b intensifies in the Verde Valley and southeast side of the Black Hills with significant momentum as cold air flowed down the Black Hills southeastern side, and D1c developed on the leeside of the Black Hills and propagated southwestwards first toward the Bradshaw Mountains and then toward Peeples Valley and Yarnell. The heating above the Black Hills and northeasterly flow from D0 in the Verde 
Valley were catalysts for the convection. In the CNTL case (Figure 11), the formation of a density current begins by 1500 MST near the Black Hills to the northeast. D1c propagated toward and flowed over the Bradshaw Mountains, where the model downscaled into another density current after the convective outflow moved over the region centered on Mount Union (near $34.4^{\circ} \mathrm{N}, 112.4^{\circ} \mathrm{W}$ ) around $1515 \mathrm{MST}$ (2215Z). Here, the density current cloud line was virtually centered on Mount Union near the crest of the Bradshaw Mountains above 7900 feet MSL. Acceleration of its motion occurs on the lee slopes to about $14.4 \mathrm{~ms}^{-1}[(54-42) \mathrm{km} /(15 \mathrm{~min} \times 60 \mathrm{~s} / \mathrm{min})]$ and by $1530 \mathrm{MST}$ it increased to a magnitude of about $22 \mathrm{~ms}^{-1}$. By $1600 \mathrm{MST}$, the density current began to slow down as it reached the base of the Bradshaw Mountains and approached the Yarnell area. However, the magnitude remained at nearly its strongest value of $20 \mathrm{~ms}^{-1}$ as it approached Peeples Valley, Stanton, and finally Yarnell (Figure 12). The wind surge moved rapidly through Yarnell, over and down the lee side of the Weaver Mountains, from 1600 to 1630 MST. A second momentum surge at 1645 MST rushed through Yarnell as well. The combination of these two surges rapidly shifted the fire motion from moving east to south and then southwest, trapping the 19 firefighters. The surges are examined further in Section 3.4.
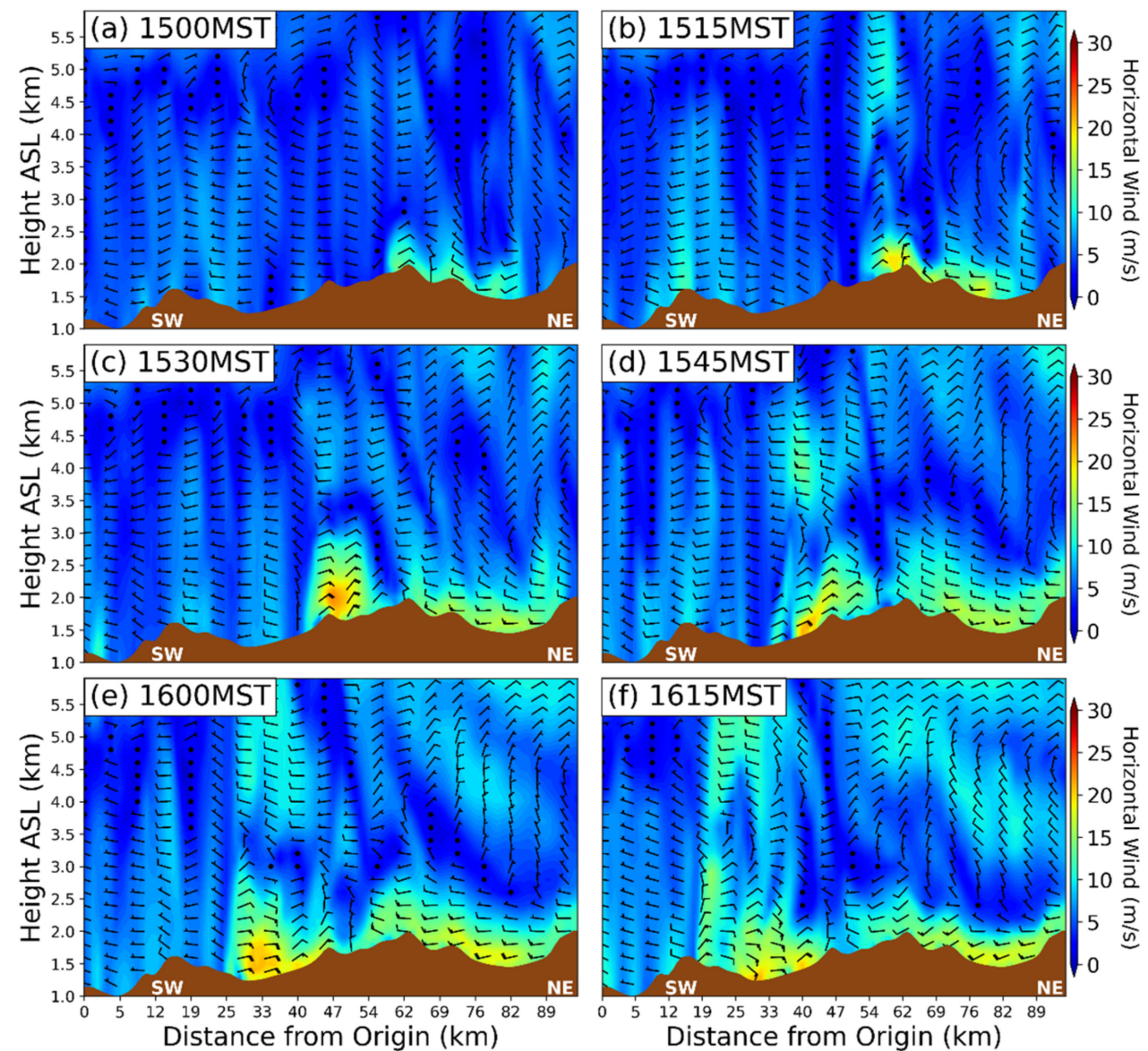

Figure 11. Shaded and barb horizontal wind for cross-section $\mathrm{H}$ extending southwest to northeast for the CNTL case 1500-1615 MST by 15-min intervals. The right-most hill is part of the Back Hills. 

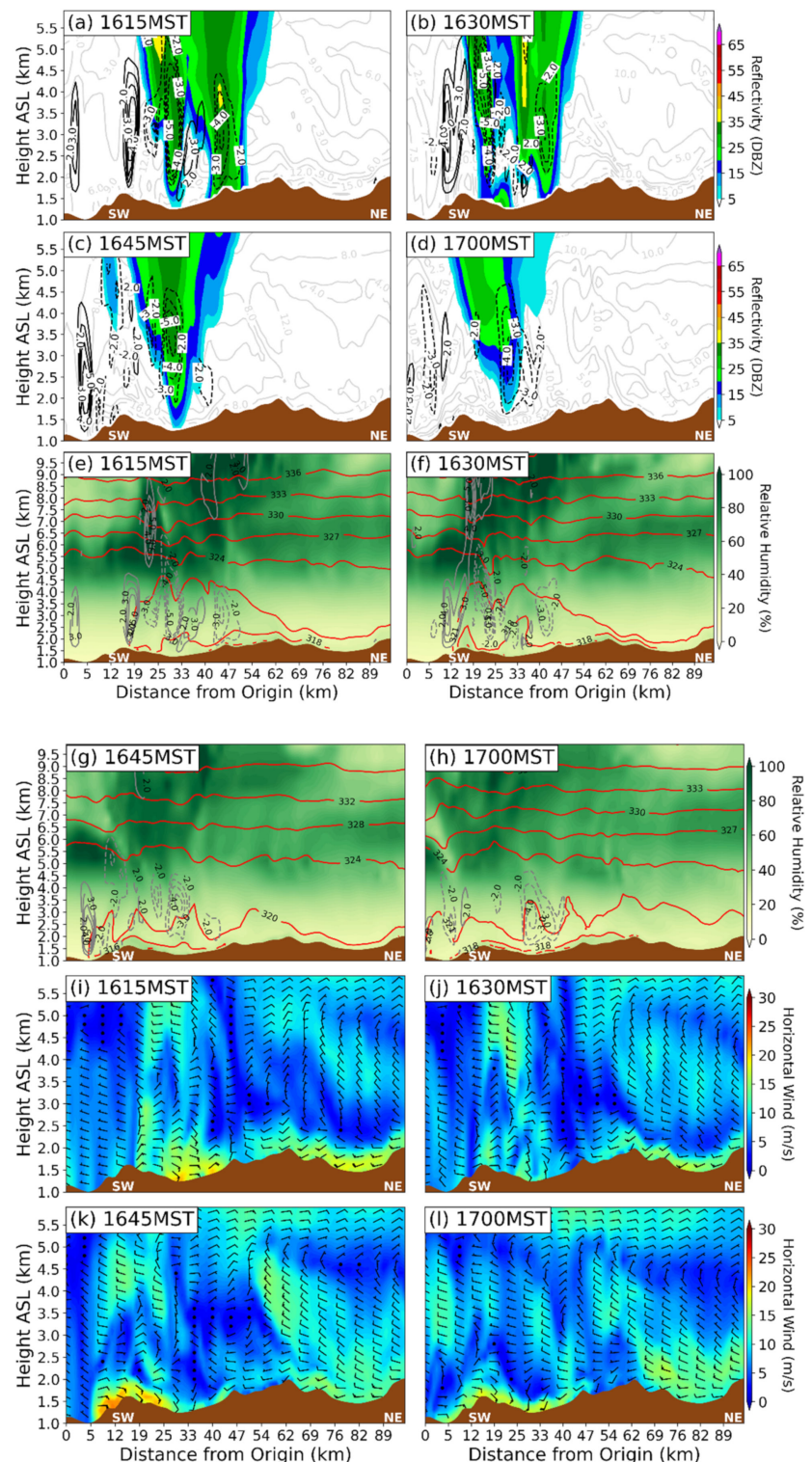

Figure 12. (a-d) Simulated reflectivity (shaded), vertical velocity (black contours), and horizontal wind (gray contours); (e-h) potential temperature (red contour), relative humidity (shaded), and vertical velocity (gray contours); and (i-1) horizontal wind (shaded and barbs) for the CNTL case from 1615 to 1700 MST by 15-min intervals. W is contoured every level from -5 to 5 excluding 0 , where applicable.

The MPS-initiated convection builds from the Black Hills over Prescott Valley and then maintains enough continuity over the Bradshaw Mountains to create a distinct line with the help of the downslope forcing of its outflow. Upslope flow around the Weaver Mountains triggered weak convection that rapidly stratiformed-out while the northeasterly flow from D1c (evident most strongly at Stanton) accelerated through the firefighter's location. The outflow boundary originating from a line of thunderstorms to the north-northeast swept over the fire area approximately between 1618 and 1630 MST. The outflow boundary moved from north to south affecting the fire area near Peeples Valley first. The effect on the fire was immediate and significant. The primary fire spread direction was forced to make a rapid south-southwesterly shift toward the firefighters' location; fire intensities and resulting flame lengths doubled while rates of spread tripled. What had been problematic fire behavior became extremely dangerous. 


\subsection{Effects of Diurnal Heating and Evaporative Cooling}

Based on the factors studied, diurnal surface sensible heating was the second-most important factor for modifying the density current generation and propagation dynamics in time moving southwestward from the Black Hills. The Black Hills' MPS signature is opposite to the other cases and weak for the NDHT case shown in Figure 10e,f. When the diurnal heating is turned off, no surface sensible heating is present. Without any surface sensible heating, no buoyancy is present, the horizontal pressure gradient is reduced, and upslope flow (which is a critical feature to the MPS circulation) is reduced/removed. The organizing mechanism for the MPS is turned off and moist convection is suppressed over the Black Hills. A density current is not generated since there is no moist convection that would create the evaporative cooling needed for the density current formation. The MPS-like signature does not evolve past the transitional stage into the developing stage in which flow fully reverses from downslope to upslope, which would be conducive for convection. Thus, an MPS solenoidal circulation is not seen.

The environment without diurnal surface sensible heating (NDHT) generates no simulated reflectivity and little to no vertical velocity (not shown). The potential temperature remains constant as well near the surface at $312 \mathrm{~K}$ at $1.5 \mathrm{~km}$ above ground level (AGL), increasing to $320 \mathrm{~K}$ by $2.5 \mathrm{~km}$ AGL. The relative humidity within the first $2 \mathrm{~km}$ AGL is between 30 and $40 \%$ and drops to $20-30 \%$ from 2 to $3.5 \mathrm{~km}$, thus further indicating the environmental uniformity. The horizontal wind near the surface was seen to be from the south, averaging $5 \mathrm{~ms}^{-1}$ and reaching a maximum of $15 \mathrm{~ms}^{-1}$ in the valley southwest of Yarnell. The horizontal wind transitions from being from the north-northwest just above the surface, averaging 5-10 $\mathrm{ms}^{-1}$ and reaching a maximum of $10 \mathrm{~ms}^{-1}$ above the lee slope of the Bradshaw Mountains, to being from the east-northeast aloft, averaging $5 \mathrm{~ms}^{-1}$ with no clear maximum throughout the time frame.

The evaporative cooling (generated by the evaporation of precipitation from the storm) played a role in initializing the density current and, to a lesser extent, the convection. This arises from the generation of a cold pool, which then initialized more convection. Thus, by turning off the evaporative cooling, no subsequent convection is initialized. From Figure 10c,d, when evaporative cooling (NEVP) is turned off, the MPS signature is still present. Just as in the CNTL case, the MPS develops during the late morning around 1000 MST. A cold pocket also develops on the lee side of the Black Hills which is seen from the isentropic expansion. The cold pocket has a similar extent, reaching from the bottom of the Verde Valley to the peak of the Black Hills. After sunrise, the nocturnal katabatic flow begins to be replaced by the mesoscale solenoidal circulation, in this case by 1000 MST. Upslope flow is produced from the horizontal pressure gradient force toward the slope with the main upward flow in the LCZ. The MPS lifts moisture which cools and forms clouds over the Black Hills. However, any convection remains constrained far above the surface $(\sim 5 \mathrm{~km})$ since the evaporative cooling process cannot act to moisten and cool the lower levels for the precipitation (and cool air) to reach the surface. Thus, no convective downburst or density current is generated.

Figure 13 shows the simulated reflectivity and horizontal wind and $w$, theta and relative humidity and $\mathrm{w}$, and horizontal wind from 1615 to 1700 MST for the NEVP case. During this time frame, no density current is generated. However, vertical motion is still present, unlike in the NDHT case. The horizontal wind is also stronger, reaching a maximum just above the surface near the peak of the Bradshaw Mountains by 1630 MST. At $6 \mathrm{~km}$ AGL, the horizontal wind is consistently stronger than in the NDHT case. Wind direction is slightly less uniform than in the NDHT case, which results from a repressed vertical velocity, but more uniform than in the CNTL case because of the lack of the density current. Similar conclusions can be reached for the potential temperature. When comparing the relative humidity and simulated reflectivity between cases to the CNTL case, the relative humidity is more uniform at $3 \mathrm{~km}$ and higher for the NEVP case and even more so for the NDHT case. The simulated reflectivity is vastly different in both the NEVP and NDHT cases compared to the CNTL case. 

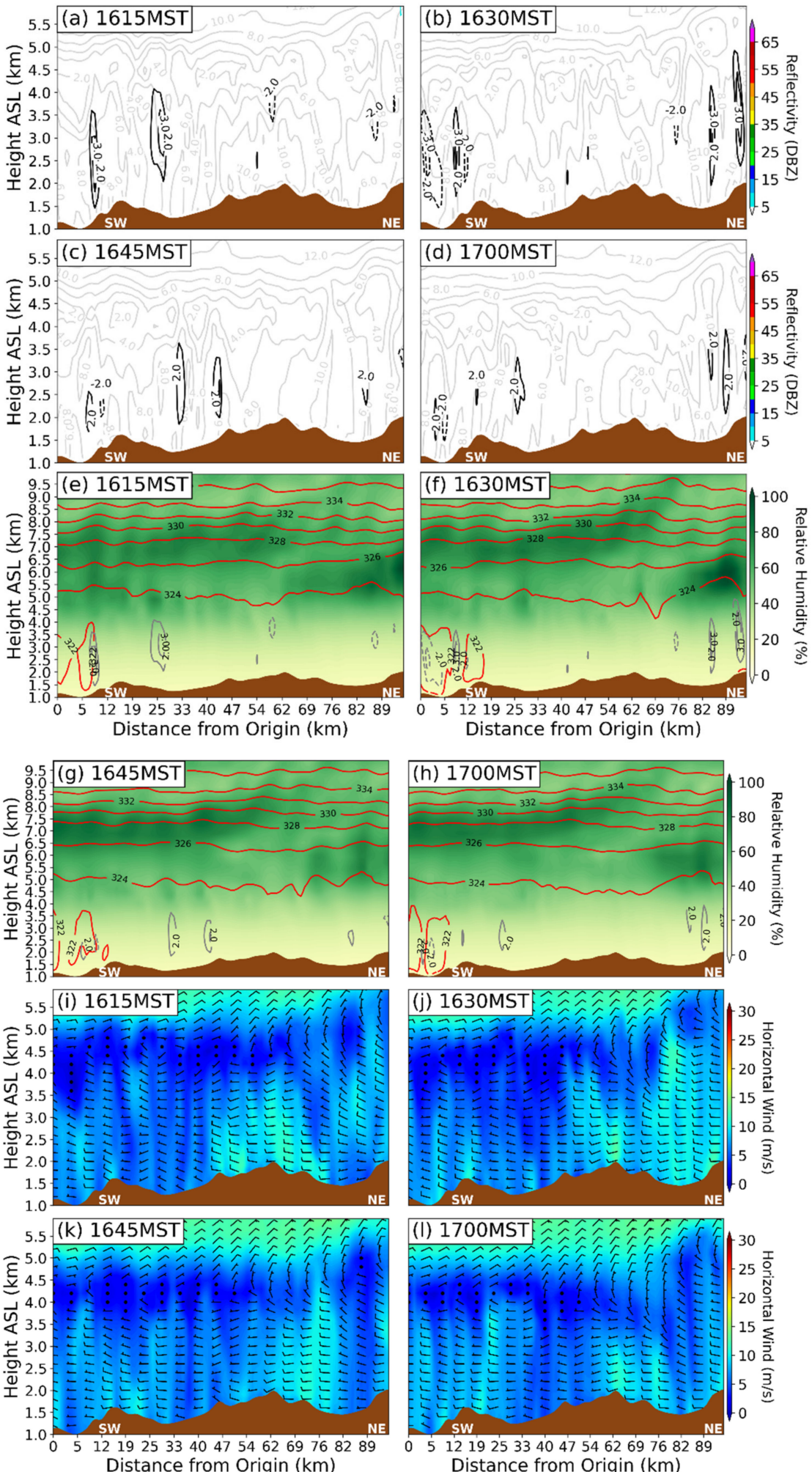

Figure 13. (a-d) Simulated reflectivity (shaded), vertical velocity (black contours), and horizontal wind (gray contours); (e-h) potential temperature (red contour), relative humidity (shaded), and vertical velocity (gray contours); and (i-1) horizontal wind (shaded and barbs) for the NEVP case from 1615 to 1700 MST by 15-min intervals. W is contoured every level from -5 to 5 excluding 0 , where applicable. 


\subsection{Effects of Complex Terrain}

Examining the simulated reflectivity and $10 \mathrm{~m}$ winds (Figure 14a), an outflow is shown that developed from convection just northeast of Yarnell (bold x) by 1615 MST. This convective cell generates two surges of momentum that divert to the south and west as the outflow encounters the isolated Weaver Mountain to the east of Yarnell. The southwarddirected surge rushed into the eastern valley while the westward-directed surge rushed into the gap between the western and southeastern Weaver Mountains with velocities of $10-20 \mathrm{~ms}^{-1}$ at $10 \mathrm{~m}$ above the ground. Examining the NSEM simulated reflectivity and $10 \mathrm{~m}$ winds (Figure 14b), the same outflow is shown developing to the east-northeast of Yarnell around the same time, 1615 MST. However, without the influence of the southeast isolated Weaver Mountain, the flow does not divert as in the CNTL case and, instead, a broader fanning of momentum occurs which is stronger $\left(15-20 \mathrm{~ms}^{-1}\right)$ but smoother (shown by the red square for the CNTL case and the NSEM case in Figure 14) that rushes west, southwest, and south, toward and through the Granite Mountain Hotshots' location just west of Yarnell (indicated by the thin $\mathrm{x}$ immediately west of Yarnell).

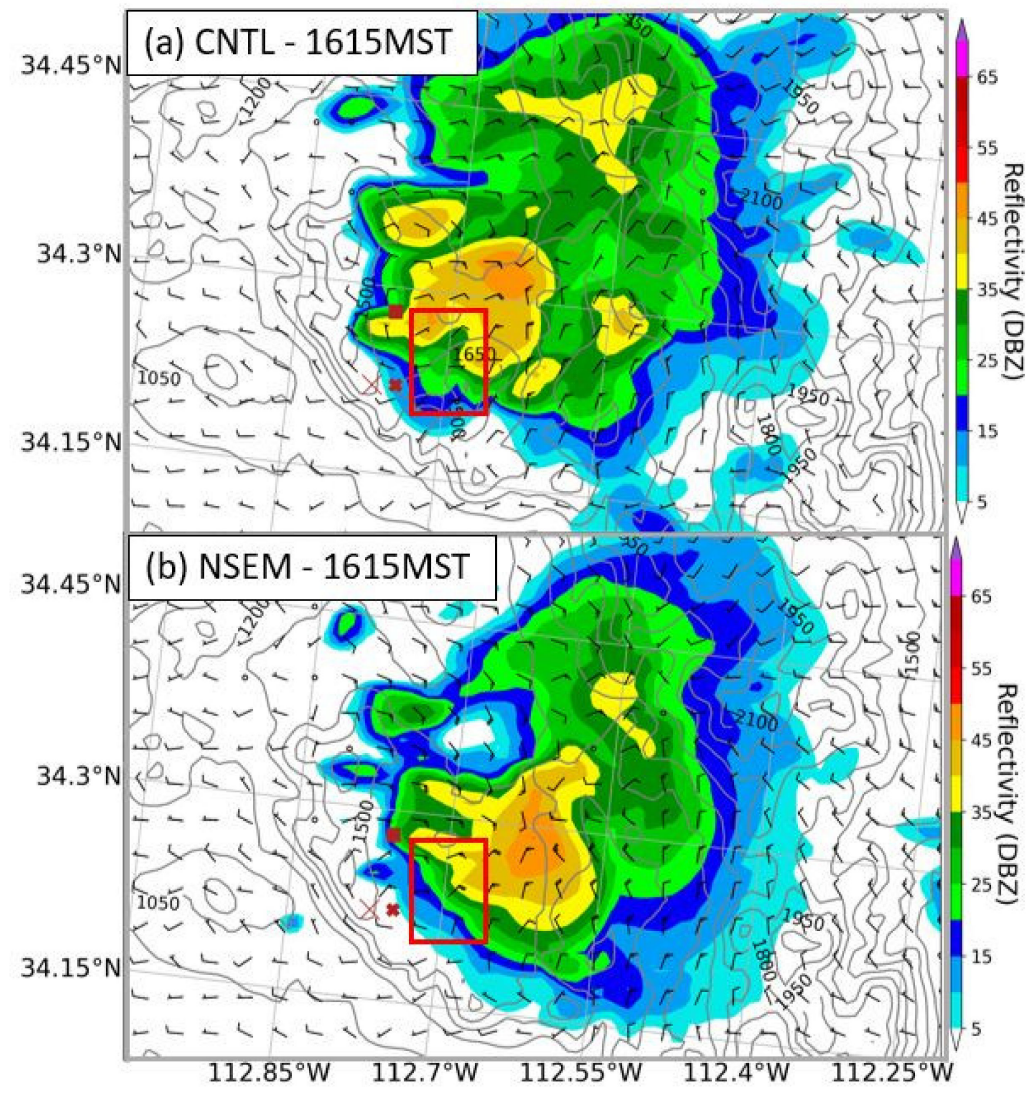

Figure 14. Simulated reflectivity and $10 \mathrm{~m}$ horizontal wind over terrain (contoured) for cases CNTL (a) and NSEM (b). The red rectangle indicates the stronger but smoother fanning of momentum in the NSEM case compared to the CNTL case.

Figures 15 and 16 show the reflectivity and $10 \mathrm{~m}$ winds as contours, wind barbs, and shaded depictions and break down the outflow for the CNTL (a-d) and NSEM (e-h) cases from 1615 to $1700 \mathrm{MST}$. In the CNTL case, the outflow was generated near $34.33^{\circ} \mathrm{N}$, $112.64^{\circ} \mathrm{W}$. At $1615 \mathrm{MST}$, the eastern portion of the outflow is deflected into the eastern valley while it is being strengthened by the density current rushing through from the northeast (NEDC). By 1615-1630 MST, the head of the NEDC (first surge) rushes through the Hotshots' location (circle), while right behind, to the northeast near Peeples Valley (square), the western part of the outflow (at $34.33^{\circ} \mathrm{N}, 112.64^{\circ} \mathrm{W}$ ) also strengthens and merges with the remains of the NEDC from the northeast. The small portion of the 
outflow that makes it over the isolated Weaver Mountain, moves southwest over the terrain, and weakens. By 1630-1645 MST, the second surge (NEDC remains combined with the western portion of the outflow) moves through and past the Hotshots' location with a more easterly component, as compared to the first surge of just the NEDC, which had a more northeasterly component.
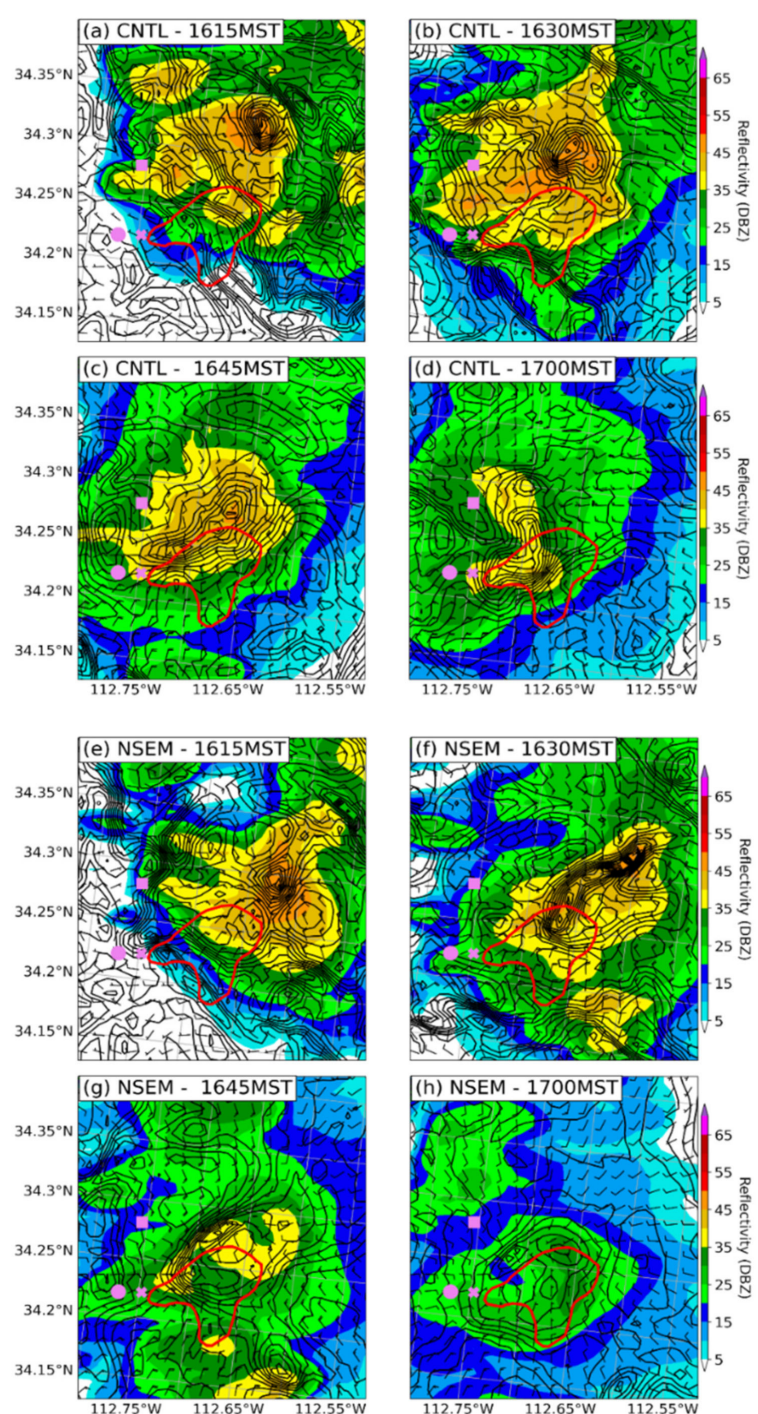

Figure 15. Reflectivity and $10 \mathrm{~m}$ wind (barbs and black contours) for the CNTL case (a-d) and NSEM case (e-h) from 1615 to 1700 MST, by 15-min intervals. The thick red outline is the location of the southeast isolated Weaver Mountain. The bold $x$ is Yarnell, the circle (immediately west of the bold $x$ ) is the incident site, and the square is Peeples Valley.

The cross-section used for the next CNTL and NSEM comparisons extending from Yarnell to just past the Bradshaw Mountains is denoted in Figure 3a. In the CNTL case (Figure 17), there is a speed reduction from 1630 to 1645 MST where the energy of the NEDC splits west and south as it encounters the isolated Weaver Mountain and merges with the outflow. The energy is more concentrated vertically than horizontally. The NSEM case (Figure 18) shows the outflow with the density current from the northeast with little to no reduction in speed as it passes over the location of the southeast isolated Weaver Mountain. Despite more precipitation in the CNTL case, the density current is simulated to be stronger in the NSEM case, which also explains the stronger surges of the NEDC and the outflow near Peeples Valley. 

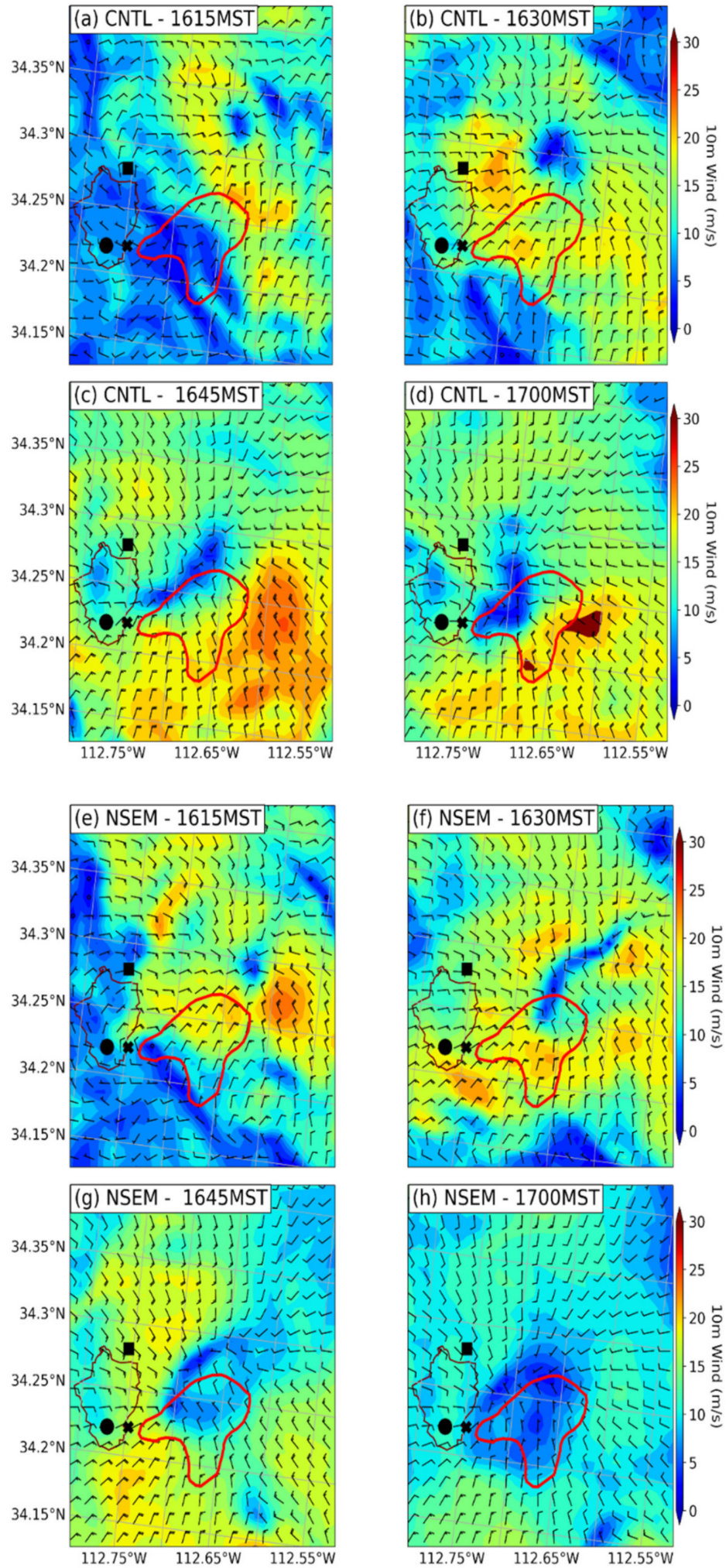

Figure 16. Barb and shaded $10 \mathrm{~m}$ wind for the CNTL case (a-d) and NSEM case (e-h) from 1615 to 1700 MST, by 15-min intervals. The thick red outline is the location of the southeast isolated Weaver Mountain, and the thin red outline is the maximum fire extent. The $\mathrm{x}$ is Yarnell, the circle (just west of the bold $x$ ) is the incident site, and the square is Peeples Valley. 

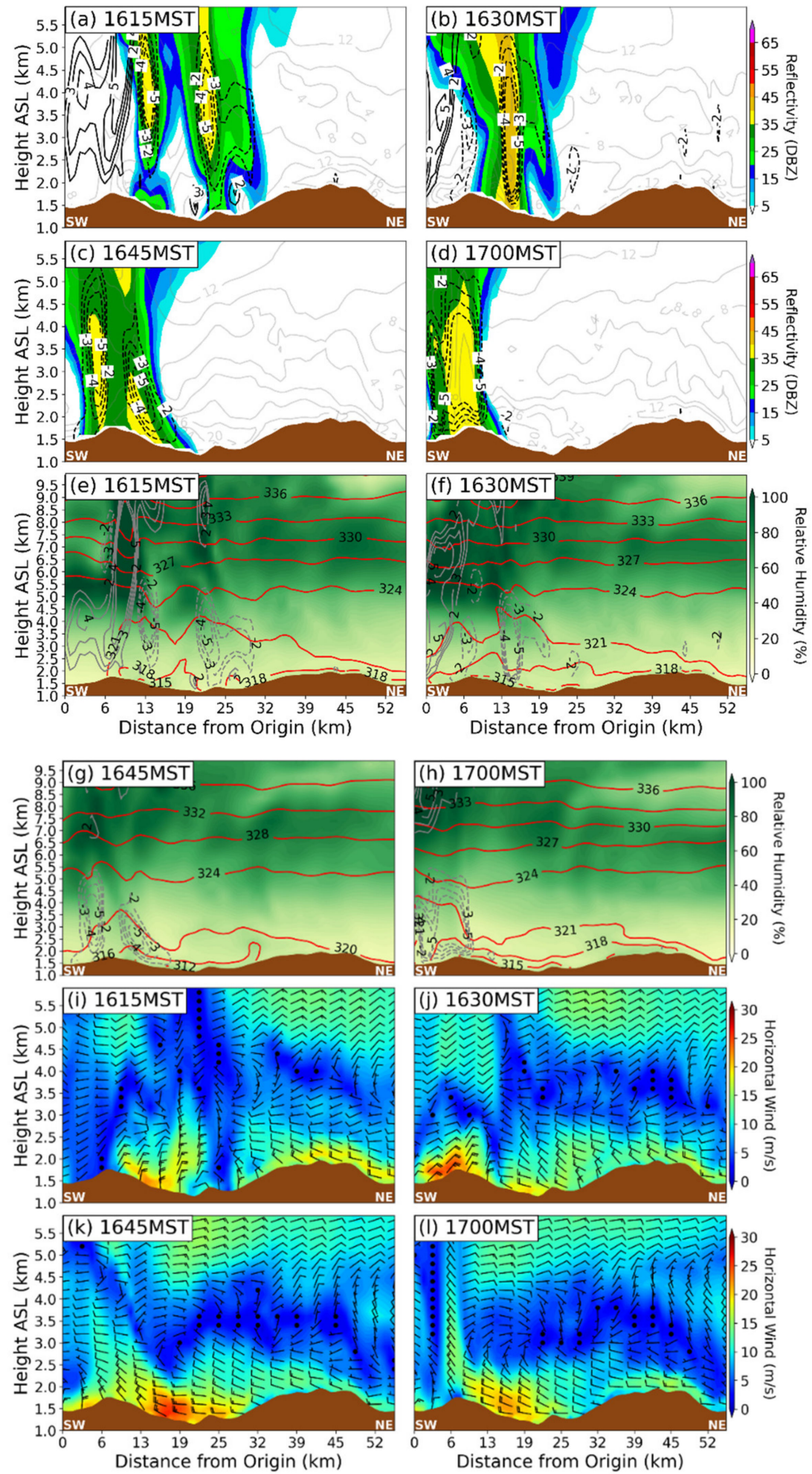

Figure 17. (a-d) Simulated reflectivity (shaded), vertical velocity (black contours), and horizontal wind (gray contours); (e-h) potential temperature (red contour), relative humidity (shaded), and vertical velocity (gray contours); and (i-1) horizontal wind (shaded and barbs) for case CNTL from 1615 to 1700 MST by 15-min intervals. W is contoured every level from -5 to 5 excluding 0 , where applicable. The cross section is shown in Figure 3a. 

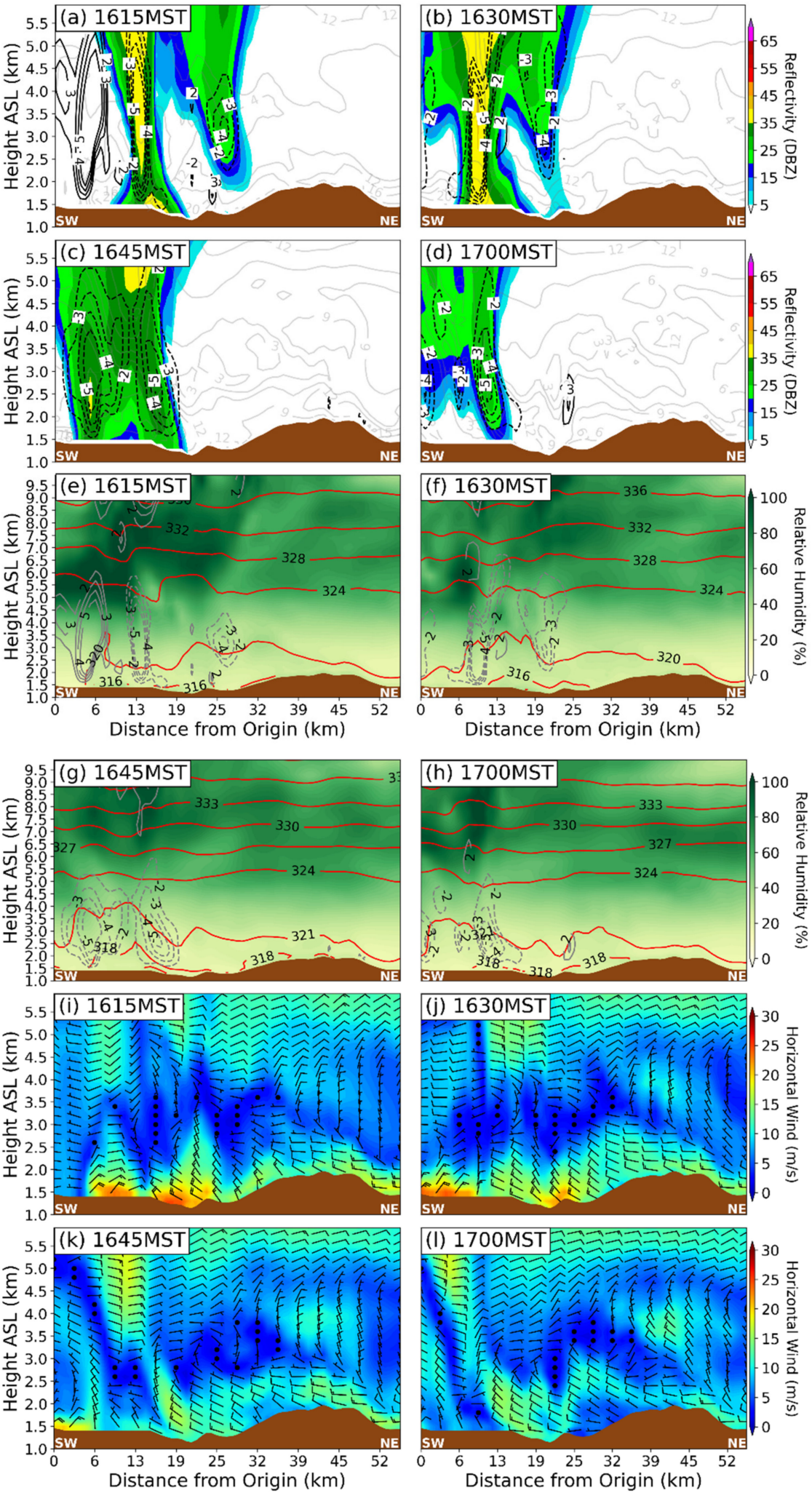

Figure 18. (a-d) Simulated reflectivity (shaded), vertical velocity (black contours), and horizontal wind (gray contours); (e-h) potential temperature (red contour), relative humidity (shaded), and vertical velocity (gray contours); and (i-1) horizontal wind (shaded and barbs) for case NSEM from 1615 to 1700 MST by 15 -min intervals. W is contoured every level from -5 to 5 excluding 0 , where applicable. The cross section is shown in Figure 3a. 
The southeast isolated Weaver Mountain acts to weaken the momentum surges that move through the Hotshots' locations. The first surge, the NEDC, splits and moves through that location from the northeast while an outflow is simultaneously generated further northeast which then merges with the remains of the NEDC and rushes through about 15 min later, with a more easterly component (second surge). The hypothesized splitting pattern was the motivation behind running the NSEM simulation to see the impact of the southeast isolated Weaver Mountain on the density current strength and propagation. From the reflectivity and winds (from Figures 15 and 16), the origins of the second surge have a resemblance to a traveling microburst signature. This leads to suggest that the surge origins were not two density currents but rather a density current and a microburst outflow.

In the NSEM case, the outflow is generated in a similar location but more south (close to $\left(34.3^{\circ} \mathrm{N}, 112.65^{\circ} \mathrm{W}\right)$ ). Likewise, the outflow strengthens with the NEDC on the eastern side of the isolated Mountain by 1615 MST. From 1615 to 1630 MST, the head of the NEDC (first surge) rushes through the Hotshots' location but slightly earlier than in the CNTL case. There is slightly less strengthening of the outflow on the western side near Peeples Valley as it merges with the remains of the NEDC, but the combination of flows ultimately becomes stronger than in the CNTL case. The portion of the outflow that moves to where the isolated Weaver Mountain would be exhibits less weakening and is maintained longer as it moves southwestward. From 1630 to 1645 MST, the second surge (again, remains of NEDC combined with the western portion of the outflow) moves through and past the Hotshots' location with a more easterly (but stronger) component as well.

\subsection{Interaction of Density Currents and Its Impacts on the Yarnell Hill Fire}

This density current that affected the Yarnell Hill Fire on 30 June 2013 originated from convective storms toward the northeast over the Black Hills and propagated southwestwards. By the time the density current reached Peeples Valley, a smaller outflow originating from a small cell near Peeples Valley merged with the density current from the northeast. The resultant density current strengthened and propagated toward and over Yarnell and the fire environment (about 1645 MST in the observations and about 1615 MST in the case of the CNTL). The isolated southeast Weaver Mountain acts to deflect the density current into two components which move south and west. Without this deflection, the density current that shifted the Yarnell Hill Fire, first southeast then south, and then southwest, would have been much stronger in total momentum but perhaps not stronger exclusively in its westerly component and anticyclonic rotational structure. Two other major factors help to generate the density current, evaporative cooling and diurnal heating. The evaporative cooling helps to form the density current while diurnal heating helps to generate wind and pressure differences for the convection that spawned the density current. The presence of the isolated southeast Weaver Mountain (NSEM) helps to dampen the density current. The next section will cover HDW effects.

\subsection{HDW Effects on the Yarnell Hill Fire}

Figure 19 shows the calculated HDW (shaded contours) during the time of the fire incident as well as the $2 \mathrm{~m}$ relative humidity and temperature (red contours) and the $10 \mathrm{~m}$ horizontal wind (barbs), i.e., components of HDW, for the CNTL case from 1615 to 1700 MST. In the CNTL case, at the beginning of the time frame (at 1615 MST), HDW (a-d) over the fire environment is relatively low at about 200-350, with higher values toward the south. When the density current passes the region of interest, HDW rises to 400-500 starting at the northeastern portion of the fire by 1630 MST and moving south-southeast over the incident site. The entire fire environment is affected by larger HDW values except for the western portion, where the western Weaver Mountains are located since the maximum value there only reaches about 300. Surprisingly, the highest HDW values in the viewing region are not at the fire but rather toward the south and southwest, in the valley. 

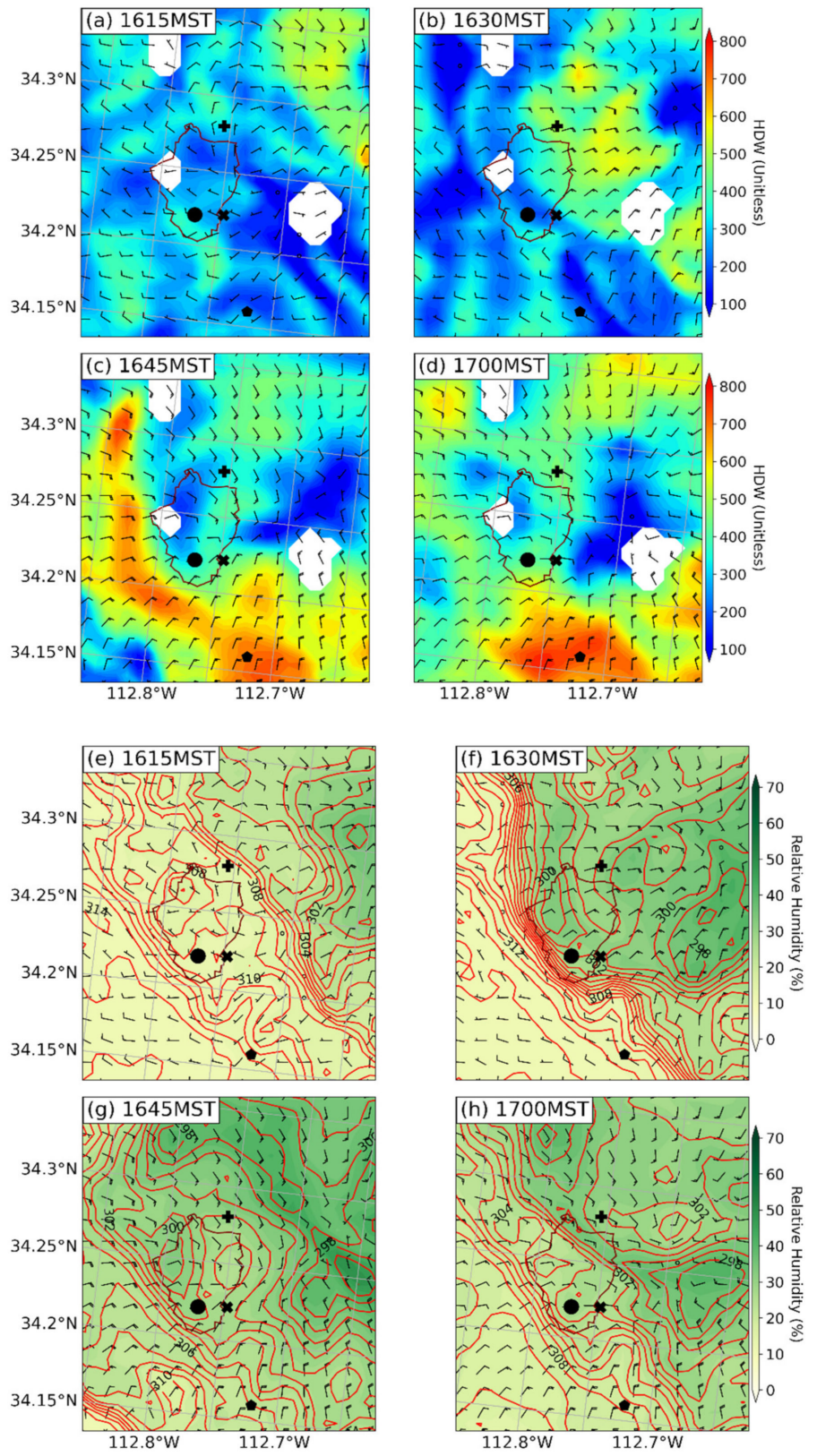

Figure 19. (a-d) HDW at $830 \mathrm{mb}$ (shaded contours) and $10 \mathrm{~m}$ horizontal wind (barbs) for the CNTL case and (e-h) $2 \mathrm{~m}$ relative humidity (shaded contours), temperature (red contours), and $10 \mathrm{~m}$ horizontal wind (barbs). These are the components of HDW for the CNTL case from 1615 to 1700 MST by 15-min intervals. White spots in a-d indicate no data (where applicable) resultant from terrain interference. The dark magenta outline is the approximate maximum fire extent. The bold $\mathrm{x}$ is Yarnell, the circle is the incident site, the plus sign is Peeples Valley, and the pentagon is Stanton.

Breaking down HDW into its individual components reveals that not all the components need to drastically increase for HDW to be high. For example, in the case of the CNTL, from 1630 to $1645 \mathrm{MST}$, at the incident site the $2 \mathrm{~m}$ temperature slightly decreases by $\sim 0.1 \mathrm{~K}$ while the dryness increases by about $5 \%$, which lead to an increase in HDW. The most significant factor is the wind factor which creates the largest HDW increase from 1645 to 1700 MST.

HDW can also be compared to the observations. From Table 4, the peak HDW, during the event, at Peeples Valley, occurs around 1725 MST with a value of 265, shortly after the last time frame in the simulations conducted in this study. The higher values from 1509 to 1539 MST can be explained by a quick wind shift, not from a density current, from 
WSW to SW that briefly advected hotter temperatures and reduced the moisture content which increased HDW for a short time (less than a 20-min period) which was not sustained long enough for significant fire effects. In Table 5 , at Stanton, the peak HDW occurs by 1701 MST reaching a value of about 570. Comparatively, the calculated HDW based on observations is lower by approximately 230 for Peeples Valley and for Stanton based on the maximum value obtained in the CNTL case. This difference can be explained by the larger simulated wind ( $7 \mathrm{~ms}^{-1}$ observed, $\sim 12 \mathrm{~ms}^{-1}$ simulated) for Peeples Valley as well as Stanton (11 ms ${ }^{-1}$ observed, $\sim 12 / \mathrm{s}$ simulated). The simulation may represent the observed wind speed worse; however, this still indicates that the wind component seems to be the most sensitive to a change in HDW. For both locations, HDW rises from 1615 to 1700 MST in both the observations and in the CNTL simulation.

Table 4. Time series of atmospheric observations near the surface at Peeples Valley, AZ, USA, on $06 / 30 / 13$. Bold indicates the approximate time of the density current passage.

\begin{tabular}{|c|c|c|c|c|c|c|c|c|}
\hline \multicolumn{9}{|c|}{ Peeples Valley $(06 / 30 / 13)$} \\
\hline Time & Altimeter & Temp. & R.H. & Wind & Dir. & Dew Point & Wind & HDW \\
\hline (MST) & (INHG) & $(\mathrm{K})$ & $(\%)$ & (mph) & (Deg.) & $(\mathrm{K})$ & (card.) & (none) \\
\hline 15:09 & 24.88 & 308.72 & 15 & 10.98 & 244 & 278.32 & WSW & 251 \\
\hline $15: 24$ & 24.88 & 309.27 & 14 & 13.00 & 215 & 277.78 & SW & 310 \\
\hline $15: 39$ & 24.89 & 308.72 & 15 & 13.00 & 250 & 278.32 & WSW & 297 \\
\hline $15: 54$ & 24.90 & 308.16 & 15 & 5.99 & 253 & 277.86 & WSW & 133 \\
\hline $16: 09$ & 24.90 & 307.61 & 16 & 9.01 & 259 & 278.33 & $\mathrm{~W}$ & 170 \\
\hline $16: 24$ & 24.91 & 307.05 & 17 & 4.99 & 341 & 278.74 & NNW & 101 \\
\hline $16: 39$ & 24.93 & 304.83 & 23 & 8.01 & 44 & 281.24 & NE & 133 \\
\hline $16: 54$ & 24.93 & 302.61 & 26 & 10.98 & 28 & 281.14 & NNE & 153 \\
\hline $17: 09$ & 24.93 & 302.61 & 26 & 10.98 & 27 & 281.14 & NNE & 153 \\
\hline $17: 25$ & 24.93 & 302.61 & 22 & 17.98 & 59 & 278.73 & ENE & 265 \\
\hline $17: 41$ & 24.91 & 303.72 & 20 & 14.99 & 9 & 278.3 & $\mathbf{N}$ & 242 \\
\hline 18:02 & 29.90 & 303.72 & 19 & 8.01 & 355 & 277.57 & $\mathrm{~N}$ & 131 \\
\hline $18: 25$ & 24.89 & 305.38 & 14 & 3.00 & 339 & 274.66 & NNW & 57.3 \\
\hline $18: 40$ & 24.85 & 305.94 & 13 & 5.99 & 247 & 274.08 & WSW & 120 \\
\hline $18: 55$ & 24.85 & 305.38 & 14 & 8.99 & 273 & 274.66 & W & 172 \\
\hline 19:10 & 24.87 & 305.38 & 14 & 4.99 & 74 & 274.66 & ENE & 95.3 \\
\hline
\end{tabular}

Table 5. Time series of atmospheric observations near the surface at Stanton, AZ, USA, on 06/30/13. Bold indicates the approximate time of the density current passage.

\begin{tabular}{|c|c|c|c|c|c|c|c|c|}
\hline \multicolumn{9}{|c|}{ Stanton $06 / 30 / 13$} \\
\hline Time & Temp. & R.H. & Wind & Dir. & Wind Gust & D.P temp. & Wind & HDW \\
\hline (MST) & $(\mathrm{K})$ & $(\%)$ & (mph) & (deg.) & (mph) & $(\mathrm{K})$ & (card.) & (none) \\
\hline $15: 01$ & 312.59 & 14 & 8.99 & 212 & 24 & 280.45 & SSW & 255.59 \\
\hline 16:01 & 311.47 & 14 & 13 & 216 & 22.01 & 279.56 & SW & 351.4 \\
\hline $17: 01$ & 308.15 & 17 & 25.99 & 20 & 41 & 279.64 & NNE & 575.34 \\
\hline 18:01 & 308.15 & 15 & 22.01 & 16 & 42.99 & 277.86 & NNE & 487.24 \\
\hline 19:01 & 309.26 & 12 & 4 & 16 & 32.01 & 275.62 & NNE & 93.22 \\
\hline
\end{tabular}


In reviewing the simulated wind speed and comparing it to observations, the CNTL simulation performed reasonably well in terms of wind direction and timing. However, for the wind magnitudes, an overall high bias was seen which was associated with weaker observed winds. The simulated winds in the CNTL case were higher than in the observations showing about 10-15 $\mathrm{ms}^{-1}$ near Cherry, AZ, USA, in the simulation (near the surface on the right of Figure 11e) but only about $5 \mathrm{~ms}^{-1}$ in the observations (Table 3). For Peeples Valley, the simulated wind magnitude showed about $12 \mathrm{~ms}^{-1}$ (Figure 16d) which was also higher than in the observations (Table 3) which indicate only about $8 \mathrm{~ms}^{-1}$. For Stanton, the simulated wind showed about $12 \mathrm{~ms}^{-1}$ in both the CNTL simulation (Figure 17d) and the observations (Table 3). The timing and wind direction agreed between the CNTL simulation (Figure 17) and the surface observations (Table 3). The findings for the wind magnitude are similar to those found in the Dude Fire [5] which had winds of $20 \mathrm{mph}$ $(9 \mathrm{~m} / \mathrm{s})$ for about $30 \mathrm{~min}$. The high bias may arise out of too coarse of a grid spacing within the WRF model, since the WRF model has higher uncertainty depending on how the model is configured [53]. This high bias could be resolved with an increased resolution. Although the highest resolution of this study (i.e., $0.777 \mathrm{~km}$ ) may still not be fine enough to fully resolve the wind magnitudes, it does provide enough detail to resolve the density current and MPS signatures, two main factors of this study.

In reviewing the simulated relative humidity and comparing to observations, the results are in alignment. The simulated relative humidity (near the surface on the right of Figure $13 \mathrm{e}$ ) is near $20 \%$ at the approximate location of Cherry which agrees with the observations from the mid to late afternoon (Table 3). For Peeples Valley, the simulated relative humidity (Figure 19h) shows values near 25\% which also agrees with the observations (Table 3). For Stanton, the simulated relative humidity (Figure 19h) shows low relative humidity values of $10-20 \%$, which, once again are in agreement with the observations (Table 3 ).

\section{Conclusions and Discussions}

This study has investigated factors that contributed to the generation of the density current and its wind shifts that suddenly redirected the Yarnell Hill Fire near Yarnell, Arizona, during the late afternoon of 30 June 2013. Four sensitivity tests were conducted using the Weather Research and Forecasting model with a minimum grid spacing of $0.777 \mathrm{~km}$ (D03). The four cases conducted were a control case (CNTL) for comparison, a case with the southeast isolated Weaver Mountain removed (NSEM) to study blocking effects, a case with evaporative cooling turned off (NEVP) to study the density current generation, and a case with the diurnal heating turned off (NDHT) to investigate the importance of daytime thermals to the generation of convection that leads to the density current.

The results have shown the remarkable similarity in convective initiation between the CNTL case and the observed radar reflectivity, where it was most vital. Nonetheless, the CNTL case still appears to be northwest biased overall in convective triggering with little to no convection toward the southeast. Fortunately, this has not significantly affected the analysis since the area of interest was relevant to the central part of the squall line that developed over central Yavapai County, AZ, USA. In the NEVP case, convection is also similarly initialized but the intensity remains weak, and the system remains stationary at the initiation location, resulting in an overall mismatch to the observed radar reflectivity. In the NDHT case, essentially no convection is generated since there is no surface sensible heating. Unsurprisingly, this case matches the least with the observed radar reflectivity.

The density current that was generated from the convection does not appear in the NEVP and NDHT cases. The convection that triggered the density current was strongly influenced by the MPS over the Black Hills which lifted moist air into the environment that spawned the thunderstorm complex and explains the origin of the convective initiation, at least for the CNTL case and the NEVP case. The MPS signature relies on surface sensible heating and the density current relies on evaporative cooling to be present. Thus, when turning off the evaporative cooling, the MPS is still present, but any convection remains 
constrained far above the surface since the lower levels cannot be cooled and moistened for precipitation to reach the surface. When turning off the surface sensible heating (diurnal heating), the MPS disappears. Thus, no convection is initialized over the Black Hills which means that no evaporative cooling was present to spawn the density current.

The Yarnell Hill Fire was affected by a sudden wind shift that rapidly redirected the fire front from moving east to south and then southwest which trapped and killed 19 firefighters. The wind shift originated from at least one density current by a thunderstorm complex that formed over the Black Hills. The wind shift origin and strength were affected by terrain and atmospheric processes. Overall, the results indicate that the effects of the evaporative cooling, which induced the pressure perturbation that generated the density current, played the most significant role in the density current generation. The effects of diurnal heating played the second-most significant role in the generation of the density current. Removing the diurnal heating removed the thunderstorm and, in extension, the density current, showing that the density current was not smoke induced nor from a front nor dryline. The effects of the southeast isolated Weaver Mountain played a role in reducing the strong mesoscale momentum and weakening the fire wind shift.

When the results were compared to the observations at Cherry, Peeples Valley, and Stanton, AZ, USA, the simulated wind magnitudes were higher than in the surface observations. The wind direction and timing, however, aligned well. The simulated and observed relative humidity at the three locations also aligned with the surface observations.

In addition to the sensitivity tests discussed, we also examined the role of HDW as a predictive tool for the fire. HDW was only explored for the CNTL case since cases NEVP and NDHT did not produce realistic wind shifts. The results have shown that HDW does predict the change in the fire environment since HDW values increase with the passing of the density current; however, a further study is needed to explore more fire-specific aspects using the WRF-Fire variant as part of the WRF model.

It is our goal in this manuscript to focus solely on the role of the environmental physical processes in causing the convectively induced rapid wind shifts that changed the environmental forcing surrounding the Yarnell Hill Fire. While we are not, in this manuscript, concerned about the feedback from explicit fire heating and related physical processes caused directly by the fire on the larger surrounding environment, the WRFFire version of the model would also help us understand the interaction of fire fuel and the atmospheric environment, if it is represented or parameterized in the model. We are focusing on the downscale environmental forcing of the fire and solely that. Additionally, the physical processes we are focusing on, while not every planetary boundary layer process, are what we consider to be the most significant elements in the low-level physical environment. Along this line of downscale modeling with a horizontal resolution of $0.777 \mathrm{~km}$, it is important to mention that a further decrease in horizontal resolution will require large-eddy simulations (LES). Here, the vertical fluxes of moisture and momentum are no longer dominative; thus, the grid resolutions in the horizontal should be comparable to that in the vertical. Additionally, the PBL parameterizations in the WRF model would be less representative of the actual PBL processes.

Author Contributions: Conceptualization, Y.-L.L., M.L.K. and J.I.; methodology, Y.-L.L., M.L.K. and J.I.; software, J.I.; validation, Y.-L.L., M.L.K. and J.I.; formal analysis, Y.-L.L., M.L.K. and J.I.; investigation, Y.-L.L., M.L.K. and J.I.; resources, Y.-L.L., M.L.K. and J.I.; data curation, Y.-L.L. and J.I.; writing-original draft preparation, Y.-L.L. and J.I.; writing-review and editing, Y.-L.L., M.L.K. and J.I.; visualization, J.I.; supervision, Y.-L.L. and M.L.K.; project administration, Y.-L.L. and M.L.K.; funding acquisition, Y.-L.L. and M.L.K. All authors have read and agreed to the published version of the manuscript.

Funding: This research was funded by the National Science Foundation, Grants 1900621 and 2022961, and NCAR/CISL for support of computing time under Project No. UNCS0030 and UNCT0001.

Institutional Review Board Statement: Not applicable.

Informed Consent Statement: Not applicable. 
Data Availability Statement: The datasets generated during and/or analyzed during the current study are available from the corresponding author on reasonable request.

Acknowledgments: The authors would like to acknowledge Gökhan Sever, formerly at Tem-poQuest, in Boulder, CO, USA, and Shu-Hua Chen at UC-Davis, CA, USA, for their insights and ideas on the evaporative cooling presented in this paper, and Justin Riley to his contribution to the early infrastructure of the modeling of the Yarnell Fire. The comments from three anonymous reviewers, which helped to improve the quality of the paper, are highly appreciated.

Conflicts of Interest: The funders had no role in the design of the study; in the collection, analyses, or interpretation of data; in the writing of the manuscript; or in the decision to publish the results.

\section{References}

1. Karels, J.; Dudley, M. Yarnell Hill Fire Serious Accident Investigation Report; Arizona State Forestry Division: Phoenix, AZ, USA, 2013.

2. Schroeder, M.; Charles, C. General Winds. In Fire Weather, a Guide for Application of Meteorological Information to Forest Fire Control Operations; USDA Forest Service: Washington, DC, USA, 1970; pp. 85-106.

3. Castro, J.; Anderson, C. A Report to the Committee on Appropriations, U.S. House of Representatives, on Wild Fire on Merritt Island. 1981. Available online: https://www.wildfirelessons.net/HigherLogic/System/DownloadDocumentFile.ashx? DocumentFileKey=de70dc82-1760-487f-b1d4-05a8d11293cc\&forceDialog=0 (accessed on 17 May 2021).

4. Haines, D. Downbursts and wildland fires: A dangerous combination. Fire Manag. Today 1988, 49, 8-10.

5. Goens, D.; Andrews, P. Weather and fire behavior factors related to the 1990 Dude Fire near Payson, AZ. In Second Conf. on Fire and Forest Meteorology; Amer. Meteor. Soc.: Phoenix, AZ, USA, 1998; pp. 153-158.

6. Kern, J.; Jones, W.; Murrian, J.; DiMaggio, J. Review of burnover incident at St. Sebastian River Preserve State Park, Indian River County, Florida 24 February 2004. Florida Department of Environmental Protection Doc. 2014. Available online: https:/ / www.wildfirelessons.net/HigherLogic/System/DownloadDocumentFile.ashx?DocumentFileKey=83ebf8a1-1d12-00 1c-32b5-d279c795fa6b\&forceDialog=0 (accessed on 17 May 2021).

7. Johnson, R.H.; Schumacher, R.S.; Ruppert, J.H., Jr.; Lindsey, D.T.; Ruthford, J.E.; Kriederman, L. The Role of Convective Outflow in the Waldo Canyon Fire. Mon. Wea. Rev 2014, 142, 3061-3080. [CrossRef]

8. Sharples, J.; McRae, R.; Simpson, C.; Fox-Hughes, P.; Clements, C. Terrain-controlled airflows. Fire Manag. Today 2017, 75, 20-25.

9. Alexander, M.; Taylor, S. Wildland fire Behavior Case studies and the 1938 honey fire Controversy. Fire Manag. Today 2010, $70,15-25$.

10. Brotak, E. The Bass River Fire: Weather conditions associated with a fatal fire. Fire Manag. Notes 1979, 40, 10-13.

11. Brewer, M.; Clements, C. The 2018 Camp Fire: Meteorological Analysis Using In Situ Observations and Numerical Simulations. Atmosphere 2020, 11, 47. [CrossRef]

12. Fovell, R.; Cao, Y. The Santa Ana winds of Southern California: Winds, gusts, and the 2007 Witch fire. Wind. Struct. Int. J. 2017, 24, 529-564. [CrossRef]

13. Fovell, R.; Gallagher, A. Winds and Gusts during the Thomas Fire. Fire 2018, 1, 47. [CrossRef]

14. Schoeffler, M.; Honda, L.; Collura, J.A. How Many Human Factors Influenced the 30 June 2013, Yarnell Hill Fire 19 Fatalities and Yet Were Never Investigated Nor Documented? In Advances in Safety Management and Human Performance; Springer International Publishing: New York, NY, USA, 2021; Volume 262, pp. 115-123. [CrossRef]

15. Hardy, K.; Comfort, L. Dynamic decision processes in complex, high-risk operations: The Yarnell Hill Fire, 30 June 2013. Saf. Sci. 2014, 71, 39-47. [CrossRef]

16. Farley, S. Modeling Wildfire Hazard with a Geographic Information System. Berkeley Undergrad. J. 2013, 26, 3. [CrossRef]

17. Paez, G.; Strojnik, M.; Scholl, M.K. Analysis of propagation of complex fire: Case of the Yarnell Hill Fire 1. Proc. SPIE 9608. Infrared Remote Sens. Instrum. 2015, 9680, 23. [CrossRef]

18. Strojnik, M.; Paez, G.; Scholl, M.K. Propagation dynamics of a mountain fire: Case of the Yarnell Hill Fire 2. Proc. SPIE 9608. Infrared Remote Sens. Instrum. 2015, 9680, 23. [CrossRef]

19. Luchetti, N.T.; Friedrich, K.; Rodell, C.E.; Lundquist, J.K. Characterizing Thunderstorm Gust Fronts near Complex Terrain. Mon. Wea. Rev. 2020, 148, 3267-3286. [CrossRef]

20. Kaplan, M.L.; James, C.N.; Ising, J.; Sinclair, M.R.; Lin, Y.L.; Taylor, A.; Riley, J.; Karim, S.; Wiles, J. The Multi-Scale Dynamics Organizing a Favorable Environment for Convective Density Currents That Redirected the Yarnell Hill Fire. Climate 2021, 19, 170. [CrossRef]

21. Potter, B.E.; Hernandez, J.R. Downdraft outflows: Climatological potential to influence fire behaviour. Wildfire Today 2017, 26, 685-692. [CrossRef]

22. Bresch, J.F.; Powers, J.G.; Schwartz, C.S.; Sobash, R.A.; Coen, J.L. Objective identification of thunderstorm gust fronts in numerical weather prediction models for fire weather forecasting. Int. J. Wildland Fire 2021, 30, 513-535. [CrossRef]

23. Markowski, P.; Richardson, Y. Mesoscale Meteorology in Midlatitudes; John Wiley \& Sons, Ltd.: Hoboken, NJ, USA, 2010. [CrossRef]

24. Lareau, N.P.; Clements, C. Cold Smoke: Smoke-induced density currents cause unexpected smoke transport near large wild Fires. Atmos. Chem. Phys. 2015, 15, 11513-11520. [CrossRef]

25. Simpson, J. Gravity Currents: In the Environ and Lab; Cambridge University Press: Cambridge, UK, 1977. 
26. Shapiro, M.A.; Hampel, T.; Rotzoll, D.; Mosher, F. The Frontal Hydraulic Head: A Micro- $\alpha$ Scale $(\sim 1$ km) Triggering Mechanism for Mesoconvective Weather Systems. Mon. Wea. Rev. 1985, 113, 1166-1183. [CrossRef]

27. Parsons, D.; Shapiro, M.; Miller, E. The Mesoscale Structure of a Nocturnal Dryline and of a Frontal-Dryline Merger. Mon. Weather Rev. 2000, 128, 3824-3838. [CrossRef]

28. Wakimoto, R. The Life Cycle of Thunderstorm Gust Fronts as Viewed with Doppler Radar and Rawinsonde Data. Mon. Weather Rev. 1982, 110, 1060-1082. [CrossRef]

29. Charba, J. Application of Gravity Current Model to Analysis of Squall-Line Gust Front. Mon. Weather Rev. 1974, 102, 140-156. [CrossRef]

30. Fulton, R.; Zrnić, D.; Doviak, R. Initiation of a Solitary Wave Family in the Demise of a Nocturnal Thunderstorm Density Current. J. Atmos. Sci. 1990, 47, 319-337. [CrossRef]

31. Koch, S.E.; Dorian, P.B.; Ferrare, R.; Melfi, S.H.; Skillman, W.C.; Whiteman, D. Structure of an Internal Bore and Dissipating Gravity Current as Revealed by Raman Lidar. Mon. Weather Rev. 1991, 119, 857-887. [CrossRef]

32. Doviak, R.; Christie, D. Thunderstorm-generated solitary waves-A wind shear hazard. J. Aircr. 1989, 26, 423-431. [CrossRef]

33. Liu, C.; Moncrieff, M. Simulated Density Currents in Idealized Stratified Environments. Mon. Weather Rev. 2000, 128, 1420-1437. [CrossRef]

34. Thorpe, A.; Miller, M.; Moncrieff, M. Dynamical models of two-dimensional downdraughts. Q. J. R. Meteorol. Soc. 1980, 106, 463-484. [CrossRef]

35. Raymond, D.; Rotunno, R. Response of a Stably Stratified Flow to Cooling. J. Atmos. Sci. 1989, 46, 2830-2837. [CrossRef]

36. Westerling, A.L.; Cayan, D.R.; Brown, T.J.; Hall, B.L.; Riddle, L.G. Climate, Santa Ana Winds, and autumn wildfires in southern California. Eos Trans. Am. Geophys. Union 2014, 85, 289-300. [CrossRef]

37. Rolinski, T.; Capps, S.; Zhuang, W. Santa Ana Winds: A Descriptive Climatology. Wea. Forecast. 2019, 34, 257-275. [CrossRef]

38. Jones, C.; Fujioka, F.; Carvalho, L. Forecast Skill of Synoptic Conditions Associated with Santa Ana Winds in Southern California. Mon. Weather Rev. 2010, 138, 4528-4541. [CrossRef]

39. National Weather Service. Glossary-NOAA's National Weather Service, Outflow Boundary. National Oceanic and Atmospheric Administration's. 2004. Available online: https://w1.weather.gov/glossary/index.php?letter=o (accessed on 4 April 2021).

40. Hermes, L.G.; Witt, A.; Smith, S.D.; Klingle-Wilson, D.; Morris, D.; Stumpf, G.J.; Eilts, M.D. The Gust-Front Detection and Wind-Shift Algorithms for the Terminal Doppler Weather Radar System. J. Atmos. Ocean. Technol. 1993, 10, 693-709. [CrossRef]

41. Dai, A. Global Precipitation and Thunderstorm Frequencies. Part II: Diurnal Variations. J Clim 2001, 14, 1112-1128. [CrossRef]

42. Dai, A.; Giorgi, F.; Trenberth, K. Observed and model-simulated diurnal cycles of precipitation over the contiguous United States. J Geophys. Res Atmos. 1999, 104, 6377-6402. [CrossRef]

43. Carrera, M.L.; Gyakum, J.R.; Lin, C.A. Observational Study of Wind Channeling within the St. Lawrence River Valley. J. Appl. Meteorol. Climatol. 2009, 48, 2341-2361. [CrossRef]

44. Tian, W.; Ozbay, A.; Hu, H. Terrain Effects on Characteristics of Surface Wind and Wind Turbine Wakes. Procedia Eng. 2015, 126, 542-548. [CrossRef]

45. Sharples, J.; McRae, R.; Weber, R. Wind characteristics over complex terrain with implications for bushfire risk management. Environ. Model. Softw. 2010, 25, 1099-1120. [CrossRef]

46. Rucker, M.; Banta, R.; Steyn, D. Along-Valley Structure of Daytime Thermally Driven Flows in the Wipp Valley. J. Appl. Meteorol. Climatol. 2010, 47, 733-751. [CrossRef]

47. Wagenbrenner, N.S.; Forthofer, J.M.; Lamb, B.K.; Shannon, K.S.; Butler, B.W. Downscaling surface wind predictions from numerical weather prediction models in complex terrain with WindNinja. Atmos. Chem. Phys. 2016, 16, 5229-5241. [CrossRef]

48. Grubišić, V.; Doyle, J.D.; Kuettner, J.; Mobbs, S.; Smith, R.B.; Whiteman, C.D.; Dirks, R.; Czyzyk, S.; Cohn, S.A.; Vosper, S.; et al. The terrain-induced rotor experiment: A field campaign overview including observational highlights. Bull. Amer. Meteor. Soc. 2008, 89, 1513-1534. [CrossRef]

49. Lin, Y.-L. Mesoscale Dynamics; Cambridge University Press: New York, NY, USA, 2007; ISBN 978-0521004848.

50. Butler, B.W.; Wagenbrenner, N.S.; Forthofer, J.M.; Lamb, B.K.; Shannon, K.S.; Finn, D.; Eckman, R.M.; Clawson, K.; Bradshaw, L.; Sopko, P.; et al. High resolution observations of the near-surface wind field over an isolated mountain and in a steep river canyon. Atmos. Chem. Phys. 2014, 1, 16821-16863. [CrossRef]

51. Hughes, M.; Hall, A.; Fovell, R. Blocking in Areas of Complex Topography, and Its Influence on Rainfall Distribution. J. Atmos. Sci. 2009, 66, 508-518. [CrossRef]

52. Menchaca, M.; Durran, D. Mountain Waves, Downslope Winds, and Low-Level Blocking Forced by a Midlatitude Cyclone Encountering an Isolated Ridge. J. Atmos. Sci. 2017, 74, 617-639. [CrossRef]

53. Skamarock, W.C.; Klemp, J.B.; Dudhia, J.; Gill, D.O.; Liu, Z.; Berner, J.; Wang, W.; Powers, J.G.; Duda, M.G.; Barker, D.M.; et al. A Description of the Advanced Research WRF Model Version 4; National Center for Atmospheric Research: Boulder, CO, USA, 2019. [CrossRef]

54. Guillory, A. ERA5. European Centre for Medium-Range Weather Forecasts. 2017. Available online: https://www.ecmwf.int/en/ forecasts/datasets/reanalysis-datasets/era5. (accessed on 4 April 2021).

55. Chen, S.; Sun, W. A one-dimensional time dependent cloud model. J. Meteor. Soc. Jpn. 2002, 80, 99-118. [CrossRef]

56. Monin, A.; Obukhov, A. Basic laws of turbulent mixing in the surface layer of the atmosphere. Contrib. Geophys. Inst. Acad. Sci. USSR 1954, 151, 163-187. (In Russian) 
57. Janjic, Z. The Step-Mountain Eta Coordinate Model: Further developments of the convection, viscous sublayer, and turbulence closure schemes. Mon. Wea. Rev. 1994, 122, 927-945. [CrossRef]

58. Janjic, Z. The surface layer in the NCEP Eta Model. In Proceedings of the Eleventh Conference on Numerical Weather Prediction, Norfolk, VA, USA, 19-23 August 1996; pp. 354-355.

59. Janjic, Z. Nonsingular Implementation of the Mellor-Yamada Level 2.5 Scheme in the NCEP Meso Model; Office Note No. 437; NCEP: College Park, MD, USA, 2002; p. 61.

60. Tewari, M.; Cuenca, R.; Chen, F.; Wang, W.; Dudhia, J.; LeMone, M.A.; Mitchell, K.; Ek, M.; Gayno, G.; Wegiel, J.; et al. Implementation and verification of the unified NOAH land surface model in the WRF model. In Proceedings of the 20th Conference on Weather Analysis and Forecasting/16th Conference on Numerical Weather Prediction, Seattle, WA, USA, 10-12 January 2004; pp. 11-15.

61. Mesinger, F. Forecasting upper tropospheric turbulence within the framework of the Mellor-Yamada 2.5 closure. Res. Activ. Atmos. Ocean. Mod. 1993, 18, 4.28-4.29.

62. Grell, G.; Freitas, S. A scale and aerosol aware stochastic convective parameterization for weather and air quality modeling. Atmos. Chem. Phys. 2014, 14, 5233-5250. [CrossRef]

63. Haines, D. A Lower Atmosphere Severity Index for Wildlife Fires. Fire Wea. 1988, 13, $23-27$.

64. Potter, B. The Haines Index it's time to revise it or replace it. Int. J. Wildland Fire 2018, 27, 437-440. [CrossRef]

65. Srock, A.F.; Charney, J.; Charney, J.J.; Potter, B.E.; Goodrick, S.L. The Hot-Dry-Windy Index: A new fireweather index. Atmosphere 2018, 9, 279. [CrossRef]

66. McDonald, J.; Srock, A.; Charney, J. Development and Application of a Hot-Dry-Windy Index (HDW) Climatology. Atmosphere 2018, 9, 285. [CrossRef]

67. Themes, E. Desert Research Institute. Western Regional Climate Center. Northern Nevada Science Center. 2020. Available online: https:/ / www.dri.edu/contact-dri (accessed on 17 May 2021). 